\title{
Towards autonomous lab-on-a-chip devices for cell phone biosensing
}

\author{
German Comina, Anke Suska and Daniel Filippini
}

\section{Linköping University Post Print}

\section{Tweet}

N.B.: When citing this work, cite the original article.

Original Publication:

German Comina, Anke Suska and Daniel Filippini, Towards autonomous lab-on-a-chip devices for cell phone biosensing, 2016, Biosensors \& bioelectronics, (77), 1153-1167.

http://dx.doi.org/10.1016/j.bios.2015.10.092

Copyright: Elsevier

http://www.elsevier.com/

Postprint available at: Linköping University Electronic Press

http://urn.kb.se/resolve?urn=urn:nbn:se:liu:diva-124074 


\title{
Towards autonomous lab-on-a-chip devices for cell phone biosensing
}

Germán Comina, Anke Suska, Daniel Filippini*

Optical Devices Laboratory, Department of Physics, Chemistry and Biology-IFM, Linköping University, S-58183 Linköping, Sweden

*Email: danfi@ifm.liu.se

\section{Keywords}

Autonomous lab-on-a-chip; cell phone biosensing; point-of-care.

\author{
Abbreviations \\ ADDCA: $\quad$ Autonomous disposable devices for cell phone analyses \\ CAD: $\quad$ Computer aided design \\ CFSB: $\quad$ Cell-free synthetic biology \\ ELISA: $\quad$ Enzyme-linked immunosorbent assay \\ HDR: $\quad$ High dynamic range \\ LOC: $\quad$ Lab-on-a-chip \\ $\quad \mu$ TAS: $\quad$ Micro total analysis system \\ MEMS: $\quad$ Micro electro mechanical systems \\ NFC: $\quad$ Near field communication \\ PAD: $\quad$ Paper analytical device \\ PCR: $\quad$ Polymerase chain reaction \\ PDMS: Polydimethylsiloxane \\ POC: $\quad$ Point-of-care
}


SPR: $\quad$ Surface plasmon resonance

SLR: $\quad$ Single lens reflex

TIR: $\quad$ Total internal reflection

ULOC: $\quad$ Unibody lab-on-a-chip 


\section{Abstract}

Modern cell phones are a ubiquitous resource with a residual capacity to accommodate chemical sensing and biosensing capabilities. From the different approaches explored to capitalize on such resource, the use of autonomous disposable lab-on-a-chip (LOC) devices-conceived as only accessories to complement cell phones-underscores the possibility to entirely retain cell phones' ubiquity for distributed biosensing.

The technology and principles exploited for autonomous LOC devices are here selected and reviewed focusing on their potential to serve cell phone readout configurations. Together with this requirement, the central aspects of cell phones' resources that determine their potential for analytical detection are examined. The conversion of these LOC concepts into universal architectures that are readable on unaccessorized phones is discussed within this context. 


\section{Introduction}

Advances in the sophistication and accessibility of biosensing solutions are central to supply current and future society's demands. For instance, the deployment and decentralization of medical diagnostics solutions hold promise in aiding medical doctors focusing on the patient's condition by providing faster and personalized diagnostics, with more accurate and frequent monitoring of critical parameters. Decentralization also implies the patient's comfort associated with home and doctors' office testing and facilitates compliance with treatment. Besides these benefits, decentralization is also an issue of economic importance and a policy to serve ageing populations in developed countries (Saltman et al. 2007; The World Population Situation, 2014; Luppa et al., 2011).

The instruments required for decentralization vary with their purpose and user setting. Thus, in vitro diagnostics systems for doctors' offices or specific hospital services can tolerate the cost and complexity of standalone dedicated platforms (Chin et al., 2012; Abgrall and Gué, 2007; Kovarik et al., 2012), whereas point-of-care (POC) devices for home and self-testing require lower costs and user friendliness (Gervais et al., 2011; Durner, 2010; Gubala et al., 2012). Concurrently, these systems also require strict analytical performance (Venge et al., 2010), quantitative detection, robustness to user skills and the ability to record and centralize results.

Standalone computer controlled dedicated instruments provide these requirements (Kovarik et al., 2012; Gervais et al., 2011; Durner, 2010; Chou et al., 2012; King et al., 2014; Ducreé et al., 2007; Madou et al., 2001, https://www.cobasliat.com) but lack the ubiquity to serve personal testing.

The pervasive presence of cell phones, with subscriptions in excess of the world's population (Global mobile statistics, 2014), and with an increasing proportion of smart phones (Nemiroski et al., 2014), implies an installed infrastructure with computing, communication and physical sensing capabilities, which could supply a vehicle for decentralized biosensing. Modern cell phones can thus eliminate the cost of integrating user interfaces, data processing and detection systems for standalone instruments.

Thus, the same type of instrument regularly interfaced to computers could be implemented with cell phones, either integrating the electronic interfacing (Nemiroski et al., 2014; Li et al., 2012; D’Ambrosio et al., 2015; Laksanasopin et al., 2015; Tropea et al., 2014; Addae-Mensah et al., 2010) or using generic digital acquisition boards for phones (https://github.com/ytai/ioio/wiki). This alternative implies complete freedom to design the instrumentation but sacrifices the ubiquity of the solution. Although cell phones are ubiquitous, the measuring instruments are scarce, and as is the combination of these two parts.

In contrast with this instrumentation approach, other solutions aim at partially or totally retaining cell phone ubiquity by excluding electronic interfacing and employing either reusable accessories 
(Breslauer et al., 2009; Smith et al., 2011; Zhu et al., 2013; Vashist et al, 2014; Mudanyali et al., 2012; Switz et al., 2014; Potyrailo, 2013; http://holomic.com) or disposable devices (Matinez et al., 2008a; Preechaburana et al., 2012a, 2014, 2015; Comina et al., 2015a) to complement cell phones for biosensing and chemical detection. These techniques dominantly exploit optical coupling to cell phone cameras, which represents a universally available resource across phone models, brands and operating systems. Image and video acquisition also provide standardized data formats, which can capture a broad range of phenomena. The chemical element in these systems should thus produce responses readable as images or video. The main approaches include microscopy and detection of intensity and color changes, as well as contrast and displacement signals and their time responses (Vashist et al, 2014; Preechaburana et al., 2014).

Reusable accessories can incorporate light sources, optics and positioning for the chemical detection element. The accessories are commonly designed for specific phone models, and existing demonstrations show strong analytical performance (Vashist et al, 2014; Wei et al., 2013, 2014). However, although the simplifications make the concept more affordable than electronically interfaced instruments, the combination of accessory and phone necessary to produce a measurement is still scarcer than the phones.

The last alternative focuses on entirely preserving the cell phones' ubiquity by adapting the sensing device to operate on any cell phone, and without accessories. These devices should be low-cost disposables with the potential to be deployable at the cell phones' scale, and it is desired that a single architecture could universally couple to any phone brand, model and operating system. Further demands include autonomy in operating the entire sample conditioning process and the creation of a reference calibration range to allow quantitative measurements while operating the phone in default configurations and integrating the coupling element within the disposable (Preechaburana 2012a, 2014; Comina et al., 2015a). This concept presents specific challenges in terms of integration and design, and this review will examine the lab-on-a-chip (LOC) biosensing that could be adapted to such end-to-end universal, autonomous and quantitative diagnostic disposables for cell phones analyses.

The information is presented following a functional organization (Figure 1), classified in sample conditioning and detection coupling solutions, along with the specific details necessary to adapt autonomous LOC principles to fully exploit the residual resources in cell phones' default configurations.

\section{Lab-on-a-chip biosensing}


Regular LOC systems utilize external pumps and valves to control conditioning protocols, and the integration of these capabilities within autonomous LOCs is an important attribute for applications such as decentralized diagnostics.

The principles for autonomous operations have been investigated independently of cell phone detection and entail the integration of multiple functions (Abgrall and Gué, 2007; Ahn et al., 2004; Qiu et al., 2009; Bharadwaj and Singh, 2013; Floiris et al., 2010; Sin et al., 2011). Figure 1 illustrates an idealized device with all the stages that would be necessary in an end-to-end disposable solution for cell phone readout. The contents in this work are discussed following the order indicated in the figure.

\section{Figure 1}

\subsection{Sample conditioning}

Sample conditioning involves all preparatory aspects to be integrated in autonomous and disposable LOCs. This includes sample extraction, which is dependent on the type of sample and, in this work, is restricted to blood, urine and saliva. Besides sample extraction or collection, separation and amplification complete the main preparatory aspects, which in the case of cell phone detection also includes the internal generation of a calibration range. This embedded calibration is necessary to make quantitative detection portable to any cell phone, which are here assumed to operate in arbitrarily set user configurations, which is a distinctive characteristic of solutions that could universally couple to unmodified phones.

The operation of such systems also implies the integrated actuation or passive transport methods necessary to implement the conditioning, which are covered in section 2.1.3.

\subsubsection{Sample extraction}

Blood provides the most complete sample for disease diagnostics (Ray et al., 2007) and can be extracted with a hypodermic needle or with a commercial finger pricker (https://www.accuchek.co.uk/gb/products/fingerprickers/index.html;

http://www.lifescan.co.uk/ourproducts/accessories/lancingdevice). Both cases require separated devices and the subsequent transfer to the sample conditioning stage. These forms of sample extraction can be the most convenient alternative in clinical scenarios or for frequent users of home testing devices; however, practical disposables for cell phone detection, especially if aimed at 
personal testing, demand usage simplification and would benefit from an integrated extraction stage.

Micro-needle arrays (Ahn et al., 2004; Gattiker et al., 2005; Khanna et al., 2008; Ganesan et al., 2014) and micro-actuators offer an alternative to sample extraction and have been demonstrated in the context of micro total analysis systems ( $\mu$ TAS) and as micro electro mechanical systems (MEMS) (Nisar et al, 2008; Liu et al., 2010).

Frequently these solutions require an external power source and entail a complexity not always compatible with low-cost disposable devices. A concept that more closely meets the demands of autonomous disposable devices for cell phone analyses (henceforth ADDCA) has been recently published ( $\mathrm{Li}$ et al., 2015). The device consists of a self-powered one-touch blood extraction system, using a polymer-capped hollow micro needle and a pre-vacuum polydimethylsiloxane (PDMS) chamber (Figure 2a). When the needle punctures the skin, it perforates the polymer cap, activating the sucking action into the evacuated chamber. The PDMS chamber is porous enough to be evacuated by simple exposure to vacuum and requires a Parylene coating to keep the vacuum inside.

The system is conceptually simple and provides a self-sufficient component made of reliable and well-established materials, which suggests a feasible integration with subsequent stages; however, the use of vacuum as energy storage presents further challenges in isolating its connection with the rest of the sampling conditioning system.

As an alternative to confined vacuum, the use of finger pumps (Comina et al., 2015a; Begolo et al., 2014; Iwai et al., 2014) could be an option to simplify this kind of extraction elements. The concept described by Begolo et al., 2014, is a 3D printed lid configured as a pump to generate positive and also negative pressure (Figure $2 \mathrm{~b}$ ). The pumping lid uses a soft seal in its construction, and although additive manufacturing strongly simplifies fabrication, this combination of materials and resolution is normally restricted to advanced and expensive 3D printers. Beyond this observation, the emergence of capable 3D printers offer a remarkable versatility for low-cost, fast-prototyping (Symes et al., 2012; Kitson et al., 2012; Comina et al., 2014a, 2014b; Shallan et al., 2014), which enables the acceleration of the development and optimization process and offers almost unlimited geometrical configurations that are otherwise accessible only to advanced microfabrication.

In the case of Comina et al., 2015a, which is also a 3D printed device, an integrated check-valve (Comina et al., 2015b) configured in series with a silicone tube provides an unlimited volume finger pump, capable of multiple cycles (Figure 2c). This device is manufactured via a low-cost, fastprototyping method (unibody-LOC, ULOC), which employs consumer grade stereo lithography (SL) 3D printers (Comina et al., 2014a, 2014b). The ULOC method transfers all complex fabrication tasks to a single monolithic 3D printout, or unibody, which hosts all other components such as the 
PDMS seat for the check-valve, the connector to the silicone tubing, and the rest of the fluidics. The devices are designed with open channels, granting easy access for functionalization, and the sub-micrometric surface finish enables sealing with regular adhesive tape (Comina et al., 2014a).

In both finger pumps, the energy source is the finger action, and problems related to storage of the energy source within the devices are entirely eliminated in these examples.

Urine samples are commonly collected in a disposable cup, from which the sample is transferred to the analytical stage. In contrast with blood, urine samples imply larger volumes, and collection using a cup is a natural alternative. In the case of reusable accessories for cell phones, an albumin urine test has been demonstrated (Coskun et al., 2013). This solution uses $150 \mu \mathrm{L}$ disposable syringes to inject $25 \mu \mathrm{L}$ urine into a PDMS detection cell containing the reagents for fluorescence detection using the phone camera interfaced with a reusable instrument (Figure 2d). The use of a syringe is a practical choice in this case, but one can imagine a lid pump (Begolo et al., 2014) operating as a suction device integrated with the rest of the fluidics, which could additionally provide precise volume metering. ULOC finger pumps are simpler (Comina et al., 2015a), but they still have not been demonstrated for suction.

An established solution that is implemented in commercial pregnancy tests involves lateral flow devices (Figure 2e) (Wong and Tse, 2009). This type of solution is not necessarily limited to a single parameter, such as has been demonstrated in modern paper fluidics (Sin et al., 2011; Yetisen et al., 2013; Martinez et al., 2008b; Osborn et al., 2010) (Figure 2f), and more advanced operations can also integrate switches and valves (Chen et al., 2012; Marinez et al., 2010). Alternatively, the capillary paper extraction can be combined with classical fluidics, as has been shown in hybrid transport systems (Wang et al., 2010; Kokalj et al., 2014), and capillary devices can be entirely microfabricated (Zimmermann et al., 2007; Safavieha and Juncker, 2013; Gervais and Delamarche, 2009).

Saliva is perhaps the friendliest non-invasive type of sample, but it also involves specific drawbacks. Saliva is collected with a substantial amount of bacteria and is produced by more than 20 glands operating at different rates and in different locations, which also can be influenced by diet (Beltzer et al., 2010). Thus, saliva collection requires following specific collection protocol and sample integration methods.

The most common forms of saliva collection include (1) the passive drool technique (Christodoulides et al., 2005), where saliva is accumulated in the floor of the mouth for a defined period of time and then spat into a test tube where some few $\mathrm{mL}$ are collected and (2) the absorbent device technique, which uses elements such as swabs to sample the saliva, which can be directly integrated into lateral flow immunoassays, such as the commercial devices used for HIV testing (Dewsnap and Mcowan, 2006; Zelin et al., 2008; Mohamed et al., 2012). 
Despite the apparent simplicity of absorbent devices, they can be affected by the spatial variation of marker concentrations within the mouth, such as in the case of a-amylase proteins (Beltzer et al., 2010), whereas the passive drool technique, although it requires following a more thorough protocol, integrates in the sample contributions from multiple locations.

In the particular context of measuring with cell phones, an important aspect is that the phone should be preserved from sample exposure. Accordingly, the integration of a suction stage could be the most convenient way to collect either urine or saliva directly from commercial saliva vials or urine cups. This configuration also enables the acquisition of other type of samples, which already have established extraction protocols for the collection within sterilized or conditioned commercial vials.

Figure 2

\subsubsection{Sample preparation}

Upon the extraction of whole blood samples, analyses typically require the separation of red blood cells from plasma. The integration of the separation stage is not only relevant for the purpose of devices for cell phone readout but also to shorten the time between separation and analysis, which is critical to reduce variability (Lauks, 1998) and to ensure plasma proteome consistency (SenYung et al., 2006).

Plasma separation in regular microfluidic setups can be achieved through different methods (Yang et al., 2006; VanDenlinder and Groisman, 2006; Haeberle et al., 2006; Fan et al., 2008), but integration into an autonomous disposable device requires the elimination of regular valves and pumps or their conversion to low-cost alternatives (Comina et al., 2015a; Begolo et al., 2014). Aside from the propulsion mechanism, a simple solution for blood separation consists of a deep trench across a microchannel, which traps the red blood cells (Figure 3a) (Dimov et al., 2011). In this case whole blood is propelled using a self-powered evacuated dead-end microchannel (Hosokawa et al., 2004, 2006), which needs to be preserved in a vacuum pouch previous to operation, although the principle could be adapted to other forms of self-propulsion (Wang et al., 2010; Kokalj et al., 2014; Zimmermann et al., 2007; Gervais and Delamarche, 2009) or finger pumps (Comina et al., 2015a; Begolo et al., 2014). The deep trench type of separation feature is also very compatible with 3D printed LOC devices (Comina et al., 2014a, 2015b) and minimizes the number of components and fabrication steps. The implemented trench, a circular well aligned with the channels, captures erythrocytes proportionally to the flow rate and takes a few tenths of a second at the maximum flow rate to clear a sample volume of $5 \mu \mathrm{L}$. The device operates between 
$2 \mu \mathrm{L} \mathrm{h}{ }^{-1}$ to $400 \mu \mathrm{L} \mathrm{h}^{-1}$, which can also be achieved by lid and finger pumps, and, besides separation, it offers multiple detection possibilities, such as hematocrit quantification, since at a fixed flow rate the optical density of the trench should be proportional to the hematocrit level.

Ratchet architectures used in integrated concentrator arrays (Park et al., 2012) are also suitable geometries for separation (Figure $3 \mathrm{~b}$ ), as well as geometrically conditioned inertial focusing principles, such as those illustrated in the next section (Martel et al., 2015).

Another suitable concept, which additionally employs a reporting strategy convenient for ADDCA, utilizes a flow-based method for plasma separation, hematocrit evaluation, and serum biomarker quantitation (Figure 3c) (Browne et al., 2011). The device entails a single channel with three different configurations: a coil shaped separation segment, a serpentine for hematocrit readout and a sector for ELISA detection. When a blood sample $(0.5-1.5 \mu \mathrm{L})$ is injected into the channel, the erythrocytes migrate axially faster and pack ahead of the plasma. Thus, when the sample passes through the serpentine, the erythrocytes' distribution reflects the hematocrit level and can be interpreted as a grey scale. This solution is attractive for cell phone readout not only because of the imaging the authors used for intensity quantification but also for its potential for more advanced and robust readout, which will be discussed in section 2.3.

When the sample reaches the third sector, only plasma is exposed to immobilized antibodies in a high surface-to-area configuration, where it is incubated for a given time and finally flushed, leaving the ELISA test ready for readout.

Lateral flow configurations are an established solution for the separation of erythrocytes using paper membranes (Wong and Tse, 2009) and have also been adapted to hybrid capillary-driven systems (Gervais and Delamarche, 2009). Among other possibilities compatible with ADDCA is the use of bead-packed microchannels (Shim et al., 2010), where erythrocyte separation occurs when red blood cells are blocked in the space between beads, while the plasma continues forward to the detection stage.

Beyond the concepts compatible with cell phone detection, there are numerous other possibilities for integrated plasma separation, which have been comprehensively surveyed in recent reviews (Hou et al., 2011; Kersaudy-Kerhoas and Sollier, 2013).

Urine samples imply diluted markers in a large volume that needs to be allotted into a smaller volume for measuring. Accordingly, the ways of collecting and concentrating the analyte are key challenges, and although sample collection is feasible with the tools discussed in the previous section, it is not always the best option for integrating sample preparation on chip. For instance, protein analysis, which is relevant to the diagnosis and monitoring of chronic conditions, demands numerous laboratory preparation steps. These include concentration and purification, which in commercial kits (e.g. ProteoSpin ${ }^{\mathrm{TM}}$ ) is performed by spin column chromatography (Matson, 2008). 
The protocols typically include $\mathrm{pH}$ adjustment and column activation, which involves centrifugation with a wash solution, and the same for sample protein binding-further washing and elution. Sample pre-treatment is also important for polymerase chain reaction (PCR) amplification (Zhang and Xing, 2007; Bartlett and Stirling, 2003), since nucleic acids must be first extracted from cells, and residual material can degrade the PCR amplification efficiency.

Diverse on-chip solutions for pre-concentration have been investigated (Mariella, 2008; Mello and Beard, 2003; Crevillé et al., 2007; Lim et al., 2010), and some of these approaches could be adapted to disposables for cell phones. Solid phase extraction using silane-coated channels (Kutter et al., 2000) is one such approach but uses electro kinetic transport. Nucleic acid purification has been demonstrated in porous monolithic polymer columns impregnated with silica particles (Bhattacharyya and Klapperich, 2005), which were configured as disposable elements and offered extraction efficiencies of about $70 \%$. Other techniques to create in situ porous polymer monoliths for passive filters (Mair et al., 2009) could be repurposed as well.

The in situ patterning of polyacrylamide gels has been reported for electrophoretic transport systems (Hatch et al., 2006; Herr et al., 2007; Kondapalli et al., 2011), which as well as magnetic beads used as the solid phase to capture antibodies and as carriers of target antigens are inspiring configurations (Inglis et al., 2004; Lien et al., 2008), if could be adapted to non-electrically interfaced transport.

Whenever cell lysis is required, from the different existing alternatives (Brown and Audet, 2008), reagent-less mechanical approaches (Di Carlo et al., 2003) and detergent lysis (Ocvirk et al., 2004; Huang et al., 2007) are the most directly exploitable for ADDCA.

A one-step device for genotyping from saliva (Pjescic and Crews, 2012) provides an appealing concept for cell phone readout. Genetic analyses summarize demanding integration challenges for any type of sample and commonly entail sample preparation, PCR amplification and analysis of the amplified fragments. Instead of solid-phase extraction, in the selected example, PCR is directly performed by inactivating the inhibitors in the sample. In addition, an inhibitor-resistant Taq mutant (Kermekchiev et al., 2009) of the Taq polymerase enzyme is used, which minimizes the incubation period. The device was tested with the identification of the 108-bp segment of the DYZ1 region within the human genome, which has application in sex determination (Jobling et al., 1997). The device is fabricated using a xurographic (Bartholomeusz et al., 2005) layout transferred to a glass substrate (Figure 3d). Saliva is collected into medical-grade water to initiate the osmotic lysis of the cells. The diluted sample is combined with the PCR reagents and a fluorescent reporting dye and follows a 42-amplification cycle, where complete lysis of the cells is attained within the first heating cycles. Fluorescence imaging of the sample during thermocycling results in distinctive amplification signatures, which identify the sex of the saliva donor. 
The controlled thermal cycling of the sample is certainly an inconvenient feature to integrate into disposable elements without electronic interfacing, but this device uses a long serpentine with variable channel width (Wittwer et al., 1994) heated to create a constant transversal temperature gradient. The design is not only an attractive simplification of the heating problem, but also the reaction spreads spatially instead of over time, and by imaging the device (Pjescic et al., 2010), the cycle-dependent fluorescence and the temperature-dependent fluorescence can be simultaneously captured.

Another interesting concept for molecular diagnostics supporting different type of samples utilizes modular in-gel PCR amplification cassettes configurable for multi-target detection (Figure 3e) (Manage et al., 2013). Modularity is achieved by isolating the detection elements, which consist of $7 \mathrm{~mm}$-long capillary tubes filed with the PCR reaction mix and gel reagents. Filled capillaries are UV photo-polymerized, and, upon desiccation, a gap between the material and the capillary inner walls is created. Capillary reaction units with different PCR elements can then be lined up in a PDMS holder. The sample is delivered to one end of the capillary line, and flows re-hydrating the gels in the whole line. Despite of the use of thermal cycling, for which a Peltier element is employed, it illustrates a versatile concept for modular functionalization, which also shares the benefits of imaging readout.

The detection of dengue-specific immunoglobulins in saliva has been demonstrated recently using a stacking flow immunoassay (Figure 3f) (Zhang et al., 2015). Lateral flow immunoassays are an established concept for self-tests (Wong and Tse, 2009); however, saliva cannot be applied directly to regular lateral flow test strips because it causes the detection colloidal particles to nonspecifically adhere to the nitrocellulose membrane (Nguyen and Moheb, 2001), and additionally antibody concentration in saliva is low and requires larger sample volumes than those handled in regular strips. The solution in Figure $3 f$ is a timed 2D paper microfluidic network (Lutz et al., 2011), which enables the autonomous delivery of the sample and conjugates from two separate paths, and the sample is transported through a fiberglass matrix that retains the proteins responsible for non-specific adhesion.

The final conditioning example demonstrates amplification and molecular recognition capabilities while avoiding thermal cycling (Figure 3g). Cell-free synthetic biology (CFSB (Smith et al., 2014; Pardee et al., 2014)) is a powerful bio-sensing concept that exploits the biochemical machinery in genetically engineered cells without the disadvantages of keeping the cells alive or dealing with issues of biosafety. Such a generic approach brings together the benefits of selectivity to pathogen-specific nucleotide sequences and signal amplification that can be co-opted from a model organism for a defined purpose. A recent example of this approach was configured for Ebola virus detection (Pardee et al., 2014), where cell-free synthetic gene networks were embedded in paper for in vitro applications. The active material is produced by freeze-drying cell-free systems, 
which integrate at the molecular level the fundamental transcription and translation properties of a cell but are sterile and abiotic and stable at room temperature and can be activated by rehydration.

\section{Figure 3}

\subsubsection{Transport / Reaction}

The control and timing of chemical reactions in LOCs can be achieved in multiple ways. It is, however, those principles that imply manual operation or passive control, which are most relevant to disposables for cell phone analyses.

Wicking materials offer an inexpensive transport alternative without pumps or auxiliary devices, and lateral flow tests are an established format for disposable self-testing (Wong and Tse, 2009). In recent years the subject has been re-visited and expanded (Martinez et al., 2008b, 2010; Chen et al., 2012; Noh et al., 2010; Lutz et al., 2013; Byrnes et al., 2013).

Paper fluidics can integrate timed sequences (Figure 4a) (Lutz et al., 2011), such as those necessary for the sample incubation, labeling and washing steps in ELISA assays. Two essential functions are demonstrated in Lutz et al., 2011: the arrival time of different reagents to a reaction zone or detection zone and the "shut off" time of each reagent from a single driving source. In addition, the control is embedded in the devices simply by the geometry of the layout and combines simple time regulators and reliable nitrocellulose substrates in the same design.

Autonomous capillary systems can also be implemented using micro fabrication techniques rather than paper, which offer the benefits of compatibility with classical LOC architectures and the use of detection principles beyond colorimetry (Zimmermann et al., 2007; Gervais and Delamarche, 2009; Safavieha and Juncker, 2013). Since in passive microfluidics the flow rate is predefined, minor device variations can compromise the performance of the filling dynamics, which demand accurate fabrication capabilities. Besides this aspect, pump flow rates can also be configured through the geometry (Zimmermann et al., 2007), and autonomous multistep immunoassays have been demonstrated on this platform (Gervais and Delamarche, 2009) that can also incorporate a paperloading pad for blood or plasma. The subject of capillary microfluidics has been reviewed and incorporates a substantial set of tools including pumps, valves, triggers and retentions, which depend on precise fabrication and surface conditioning for operation and can essentially integrate the same functionality as in the paper examples.

Hybrid approaches, where paper is used as a pump in otherwise conventional fluidics, have also been demonstrated (Figure 4b) (Kokalj et al., 2014). Systems like this create a suction pump using 
a working fluid between two passive valves that connect on one side to a paper sector and to an analytical region on the other end. When triggered by finger pressure, the working fluid breaches the connection to the paper side and becomes absorbed, creating suction in the analytical channel.

Other hybrid self-powered devices using filter paper as passive pumps have been implemented for the quantitative multiplexed detection of proteins from whole blood (Figure 4c) (Wang et al., 2010). Functionalization is produced on glass slides using DNA barcodes (Fan et al., 2008), which serve as substrates for the microfluidics made in the photo curable hydrophobic polymer NOA-63. Prior to use, not only the sample but also the reagents must be loaded in the chip wells. Once loaded, the capillarity of the paper sequentially drives the sample and reagents through the chip, automatically performing all the preparative steps of an ELISA test. Red blood cell separation occurs by inertial focusing, induced by flowing the sample through a narrow channel into an expansion, where the barcode stripes are thus only exposed to serum. The readout of the $20 \mu \mathrm{m}$ wide barcode lines requires a microarray scanner.

Phaseguides offer another elegant and powerful alternative to passively controlling flow using simple fabrication tools. Phaseguides are static geometric features that control the progress of a flow by conditioning the interfacial tension (Figure 4d) (Vulto et al., 2011; Hakenberg et al., 2012). They offer complete control over the filling and emptying of arbitrary architectures by a controlled step-wise advancement of the liquid-air interface using the meniscus pinning effect, and it has been demonstrated as being capable of passive valving, metering and mixing.

\section{Figure 4}

A compact alternative for multiplexed fluidics, without pumps or valves, is the concept of SlipChip (Figure 4e) (Du et al., 2009; Shen et al., 2010). Here, two plates are set in contact, with one containing micro wells with reagents confined within an immiscible carrier fluid and an array of disconnected ducts. The second plate contains a matching array of micro wells, which is complementary to the ducts in the first plate, and forms a continuous path to load the sample simultaneously into all wells. To expose the sample wells to the reagents, the upper plate is simply "slipped" with respect to the lower one, confining the sample volumes and presenting them to the reagents. Du et al., 2009, proposed this concept as suitable for cell phone imaging, essentially as a colorimetric or intensity reader, and the concept has also been demonstrated for immunoassays (Liu et al., 2010). The evolution of this concept into a digitally coded response (Shen et al., 2010) makes it even more attractive for cell phone readout, such as is discussed in section 3.2 
The SlipPAD (Liu et al., 2013) is the paper analytical device (PAD) version of the SlipChip, and it uses chromatographic paper, whose layout is configured with a wax printer. The paper layers are attached to solid plates to operate in the same way as the SlipChip. In the SlipPAD example, the multiplexed geometry is configured to integrate on-chip calibration and multiple replicates, which is an important feature for quantitative cell phone readout. Event at the development stage these devices have been produced with inexpensive infrastructure at less than 1 USD/device and at a rate of 200 devices/hour with a single printer, which is especially attractive to support small productions of specialized applications.

Not only passive but also active self-powered autonomous chips have been demonstrated (Figure 4f) (Qin et al., 2009). The integrated power source is compatible with disposable devices and consists of a catalytically triggered chemical reaction. A finger push of a $\mathrm{Pt} / \mathrm{Ag}$ pin into $\mathrm{H}_{2} \mathrm{O}_{2}$ solution triggers the generation of oxygen pressure to drive the fluidics. Depending on the initial $\mathrm{H}_{2} \mathrm{O}_{2}$ concentration, the generated $\mathrm{O}_{2}$ produces an expansion of up to 100 times the initial volume. A mechanical control mechanism is embedded in the architecture, which enables the supply of a regulated pressure. When local pressure bursts displace the solution the reaction is interrupted, and when the pressure drops the pin is re-immersed, thus generating a modulated driving pressure for up to $90 \mathrm{~min}$. This device was demonstrated for whole blood analysis, performing plasma separation in skimming channels, which requires $10 \mu \mathrm{m}$-wide channels and uses DNA barcode detection, demanding a gene chip scanner for readout. Despite the readout characteristics, the self-propulsion principle could be directly migrated to ADDCA devices.

Finger-powered microfluidics (Iwai et al., 2014; Begolo et al., 2014; Comina et al., 2015a; Qiu et al., 2009) systems are another possibility for integrating a pressure source for autonomous disposables. These systems attempt to overcome some of the limitations of capillary systems, such as small forces and slow responses, besides that capillary systems are limited to sample volumes smaller than the internal volume of the device (Begolo et al., 2014). Moreover, finger powered devices operate with architectures compatible with those used in regular microfluidics with external pumps.

Some applications, like micro droplet formation, require multiple pressure sources and wellcontrolled flow rates, and such a possibility has been achieved via a system actuated with a single pressure point (Figure 4g) (Iwai et al., 2014). The system is capable of pressures up to $7.6 \mathrm{kPa}$ and unfolds a single pressure point into multiport infusion systems that have been implemented both in multilayer soft lithography and injection molding technology. The single pressure head infuses multiple fluids into parallel branches, which with the help of check-valves, flow from inlet ports into storage chambers. The design requires two types of check-valves for each branch in order to create the suction that drives the sample when the finger pressure is released and implies sophisticated fabrication efforts. 
The emergence of modern additive manufacturing resources facilitates innovative solutions and the ability to evolve prototypes at affordable costs (Begolo et al., 2014; Symes et al., 2012; Kitson et al., 2012; Comina et al., 2014a, 2014b; Shallan et al., 2014; Wang et al., 2014; Waldbaur et al., 2011; Tseng et al., 2014; Tumbleston et al., 2015). A finger pump that exploits 3D printing technology is the pumping lid concept (Begolo et al., 2014). The method operates through the controlled compression or expansion of gas, which can be used to generate positive or negative pressure (Figure $2 \mathrm{~b}$ ). The sample is delivered to a device inlet on which the lid is attached and pressed down to its retention, thus creating an isolated positive pressure. Conversely, if the lid is pull up it creates a negative pressure in the inlet space. 3D printed lids contain a soft material seal and together with the lid seat they can be precisely configured to introduce multiple pressure steps or to produce the coordinated operation of multiple pressure ports.

The last finger pump concept is perhaps the simplest, and it is also implemented as a 3D printed device (Figure 4h) (Comina et al., 2015a). One particular aspect of this device is that it requires only a consumer grade SL 3D printer to fabricate not only the pump but also the entire ULOC fluidics (Comina et al., 2014a, 2014b) as well as the integrated coupling optics for cell phone readout. It utilizes an asymmetric seat for a PDMS element that constitutes a check-valve (Comina et al., 2015b). The area of this element is essentially the entire footprint demanded from the layout, which is substantially smaller than other alternatives. The check-valve seat is monolithically linked to a connector on one side and to the fluidics on the other. The connector is prepared to tightly plug into a silicone tubing, which when pressed displaces the sample in the check-valve in the forward direction, and when it is released, the backward flow is prevented by the check-valve action. This allows unlimited pumping volume in repeated pumping actions, which makes the design easy to accommodate to varied fluidic designs, and it also allows for regulation of the pumping pressure by selecting the distance from the ULOC connector where finger pressure is applied. This device uses a $5 \mu \mathrm{L}$ sample volume as carrying fluid and mixes two separated reagents. In addition to the sample evaluation it integrates a two-point calibration range with embedded analyte concentrations. In order to operate the device, the three concentrations react simultaneously when driven in a series configuration, which uses trapped air as a plunger to drive contiguous sectors. This solution is an alternative better suited to $3 \mathrm{D}$ printed geometries than the parallel-branched architecture used in classical configurations.

\section{Readout}

Once all preparatory steps have been completed, the following process entails a chemical reaction that produces a recordable output. In modern smart phones, readable responses are not limited to optical principles, although this is the dominant approach for universal coupling without electronic 
interfacing, and certainly for ADDCA. Color and intensity changes are the most used type of responses; however, as will be discussed here, they underexploit cell phone resources and, if used in combination with time and position detection, can produce more robust quantifications using literally the same acquisition device.

Here, the most convenient principles for cell phone readout will be discussed whether they have already been demonstrated in this form or whether they have the potential to operate in such mode.

\subsection{Optical readout}

Cameras on cell phones share common aspects that are important for conceiving generic strategies for universal device readout. In addition, phones and cameras are continuously evolving, but some features show fast progress, whereas other aspects remain mostly unchanged through product generations.

Cell phone cameras use Bayer filters for color detectors and capture images at a 24-bit color resolution, which implies red, green and blue channel intensity resolved in 256 levels. This feature has remained unchanged throughout all smart phone generations and previous phones with color cameras, and although digital SLR cameras are now equipped with 12- and up to 16-bits/channel resolution, this is not necessarily a feature that will migrate soon to cell phone cameras.

On the other hand, the dynamic range of camera detectors has increased by introducing better detector technologies, larger pixels or high dynamic range (HDR) (Reinhard et al., 2010; http://web.media.mit.edu/ hangzhao/papers/moduloUHDR.pdf, 2015) acquisition capabilities. Although this constitutes an improvement that can be used to boost the resolution of an intensity measurement, such as has been demonstrated for cell phone readout of commercial NT-proBNP lateral flow devices (Preechaburana et al., 2011b), there are better characteristics of the same detectors from which to profit.

The same can be said with respect to colorimetric detection. The three filters for color acquisition have wide and overlapping spectral bands resembling the standard color observer characteristics (Filippini and Lundström, 2004, 2006; Malik et al., 2009; Wyszecki and Stiles, 1982; Macken et al., 2006; Preechaburana et al., 2015). Accordingly, digital colorimetric acquisition is spectrally poor and susceptible to metameric artifacts, which lead to the interpretation of diverse spectral stimuli as the same color. This limitation can be overcome via complementary illuminations and the use of spectral reconstruction methods (Westland and Ripamonti, 2004); however, as mentioned before, there are better alternatives than attempting to purely quantify the responses by intensity or color. Both pixel count and frames per second (fps) in video acquisition are associated with the 
increasing computing power in cell phones and show improvements with phones' evolution - from $320 \times 240$ pixel web cameras at the beginning of the 2000s to the present cell phone front cameras that can capture video at 30fps and 720p standard while supporting snapshots at more than $1 \mathrm{MP}$ and up to 5 MP. Concurrently, rear side cameras are above 12MP in flagship models and support video acquisition in full $\mathrm{HD}$, as well as $60 \mathrm{fps}$ and slow motions modes of $240 \mathrm{fps}$ (https://www.apple.com/iphone/compare/; http://www.samsung.com/us/explore/galaxy-s-6features-and-specs/). These two dimensions exceed the resolution of intensity recording in cell phones and only require adapting the response principle to capitalize on them for ADDCA readout.

One such example involves the detection of angle resolved surface plasmon resonance (SPR) (Figure 5a) (Preechaburana et al., 2012a). SPR (Schasfoort and Tudos, 2008) is the benchmark principle in biomolecular interaction analysis and bio-sensing instruments (Homola, 2008). In an SPR experiment a visible photon is optically coupled to a plasmon on a thin metal film. The phenomenon can be observed as a characteristic dip in total internal reflection (TIR), where the illuminating angle and wavelength coordinates of the dip are sensitive to the metal surface conditions. Chemical functionalization of the metal surface renders dip coordinates sensitive and selective to target analytes.

\section{Figure 5}

SPR is normally found in laboratory instruments but also exists in commercial compact versions (Homola, 2008), and for cell phone readout it has even been implemented using a disposable optical coupler (Figure 5a) (Preechaburana et al., 2012a). This coupler collects red light from the cell phone screen and conditions TIR illumination within an angular range around the SPR dip for aqueous solutions. The coupler guides the reflected light to the cell phone front camera, which acquires a snapshot of the angle resolved SPR. Changing the screen color, the angle resolved SPR can be acquired for different energy bands.

This type of SPR signal has a number of advantages with respect to intensity or color detection. First of all, the quantification of the response depends on the coordinates of the SPR dip, not on its amplitude. The difference is that the coordinates can be resolved in more than 1000 pixels in modern phones, whereas the intensity range is limited to 256 levels for the same device. SPR sensorgrams consists of the time response of the SPR dip coordinates, and again, video recording can resolve such response at $33 \mathrm{~ms}$ intervals. Other advantages of SPR detection entail the possibility to operate with the 300 nits illumination available from any cell phone screen and also that the image of the dip is a contrast pattern that fits within the dynamic range of any phone camera. This example illustrates how the choice of the detection technique can optimize the 
exploitation of cell phone resources, which in the demonstrated detection achieves a resolution of $2.14 \times 10^{-6} \mathrm{RIU}$ and a limit of detection for $\beta 2$ microglobulin of $0.1 \mu \mathrm{g} \mathrm{mL}^{-1}$.

SPR is not the only principle that could exploit this type of response, and diffusion reactions could employ the same phone resources (Figure 5b) (Gerber et al., 2014). Also serving ADDCA requirements, the use of chemical diffusion and reaction to record temporally varying chemical information can be achieved without the need of external power. In addition, the diffusion process offers the possibility to capture the time dimension through the spatial location of the response, thus disentangling the detection from the readout process. For instance, detectors based on this principle could act as distributed recorders, similar to exposure badges and dosimeters, to be read in situ with a phone.

The demonstrated devices consist of a confined porous diffusion channel (0.5\% agar gel) with a reservoir at one end and an open path at the other end. The reservoir is preloaded with a time indicator reagent that diffuses in the porous channels at a known rate. The free side of the channels is exposed to the target analyte, and both diffuse in opposite directions. When both diffusion fronts meet an irreversible reaction occurs, leaving a response band in the porous channel. The demonstrated concept addressed the detection of lead ion in water and was configured for a recoding range of $2 \mathrm{hs}$. As indicated by the authors, the platform can be tailored to diverse types of reaction schemes, where the profile of the reaction zones can also render valuable information.

In the previous section, the SlipChip concept was discussed in its original formulation; however, there are two further developments of this concept that best match the ADDCA tenets. Despite the fact that the first example illustrates PCR amplification, which requires external thermal cycling (Shen et al., 2010), it shows the possibility to reconfigure the SlipChip for digitally coded responses. In such cases the SlipChip was read in an epi-fluorescence microscope and required multiple pictures to cover the entire response area, but permits to digitalize the concentration of target DNA as the number of responsive wells. Thus, the approach converts intensity into a pattern that can be better resolved in pixels counts than in the intensity range available in cell phone cameras. The example illustrates an attractive possibility for rendering responses that are robust to uncontrolled illumination. One can imagine a colorimetric quantitative digital pattern generated either in the SlipChip or SlipPAD that could be read directly as a phone picture, without alignment, under ambient light and with no other accessory. Distributed detection schemes such as those presented in section 2.1.2 (Figures $2 \mathrm{c}$ and $2 \mathrm{~d}$ ) also share these advantages.

Another suitable response type has been shown in the V-chip concept (Song et al., 2012). The Vchip uses an oblique slide SlipChip design, and it has been demonstrated for a multiplexed ELISA configuration. The remarkable aspect of this concept is that it also generates its own interpreted 
readout in the form of the displacement of an ink column. The device uses catalase as an ELISA label, which is put in contact with $\mathrm{H}_{2} \mathrm{O}_{2}$ and produces a proportional $\mathrm{O}_{2}$ pressure that acts against the reporting ink reservoir connected to a microchannel. Figure $5 \mathrm{c}$ shows the SlipChip loaded with sample and reagents before operation (left panel). When the device is diagonally slipped, labeled sample is put in contact with $\mathrm{H}_{2} \mathrm{O}_{2}$ and with the ink reservoir (right panel), while starting the generation $\mathrm{O}_{2}$ pressure. Thus, the displacement of the ink column reports the $\mathrm{O}_{2}$ pressure, which is proportional to the ELISA response. The columns are conceived for visual inspection but hold the same advantages as any displacement reporting principle: They are robust to uncontrolled illumination and give a response that can be resolved in pixels, which can correspond to a resolution better than 256 levels (Figure $5 \mathrm{c}$ ).

The last optical readout example corresponds to an enzyme- based colorimetric glucose test (Figure $5 \mathrm{~d}$ ), whose fluidics was described in the previous section. The device is a ULOC disposable that sits on the screen and aligns the detection zone with the front camera, wherever this is located in the phone layout (Comina et al., 2015a). This approach contributes to the universality of the solution, but cell phone cameras cannot focus at few millimeters from the camera, and a 3D printed lens is included in the design. Optics is in general not easy to custom make, and thus low cost focusing elements (Preechaburana et al., 2012b) and simplified fabrication alternatives have been investigated in the past (Love et al., 2001; Sun et al., 2005; Preechaburana et al., 2011); however, in this case lenses are simply geometrically designed in CAD, 3D printed with a consumer-grade platform, and ready to use without mechanical or chemical polishing.

The 3D printed lens refocuses the detection zone, which includes the sample and two calibration responses, on a wide range of cell phone cameras, but it uses ambient light for illumination. Since the location and distribution of the illumination cannot be controlled, it can introduce spurious background modulations that can affect the quantitative readout. Instead, the combination of the two enzymes glucose oxidase (GOx) and horseradish peroxidase (HRP) enables the consumption of the color product of the glucose detection (pink resorufin, which is a substrate for HRP), creating a peak in the response, whose time coordinate is proportional to the glucose concentration. This peak time is independent of its absolute amplitude and is thus robust to background illumination; additionally, it can be resolved at $33 \mathrm{~ms}$ in the video acquisition, which improves on the 256 intensity levels, using the same device. The proof of concept showed the possibility of a quantitative ADDCA implementation within the clinical range relevant for glucose analyses.

\subsection{Other readout possibilities}


Modern smart phones are profusely equipped with advanced physical sensors, wireless communication capabilities and computing power to couple to different phenomena for chemical detection.

Optical readout is clearly the one that offers the simplest interfacing, since image and video acquisition are regular resources in the operating systems, and, in addition, it can be operated with default applications that also deliver standardized data formats. For those implementations that utilize illumination from cell phone screens, the command of such illumination is even simpler than image acquisition. Displays are made to render arbitrary imagery, in a way completely transparent to the user, and thus a timed illuminating sequence can be simply a YouTube video uploaded on to the Internet, a self-contained .gif animation, or an application in the phone.

Near field communications (NFC) is also a feature present in numerous smart phones. It was conceived to wirelessly communicate between devices and for services such as mobile payment. In addition, NFC can link to low cost disposable tags, which integrate resonant circuits that couple phone energy for readout. In a recent development that uses NFC for gas sensing, the coupling operates at $13.56 \mathrm{MHz}$, and commercial NFC tags were functionalized for $\mathrm{NH}_{3}$ and $\mathrm{H}_{2} \mathrm{O}_{2}$ semiquantitative detection (Figure 5e) (Azzarelli et al., 2014). Disrupted tags show characteristic amplitude and distribution of the reflection coefficient peak, which can be used to monitor the analyte presence with non-line-of-sight requirements; however, these features are less evident from the cell phone readout, which characterizes only the response by the power transfer magnitude. This limitation is common to the numerous resources embedded in cell phones, which despite being present at the hardware level, they cannot be fully accessed via the standard resources of the operating systems.

Due to the inherent deployability of NFC tags, the concept is promising for distributed environmental sensing, although its adaptation for LOC response transduction might also be feasible.

A dominant feature in modern smart phones are touch screen interfaces. These are projective capacitance displays that identify touches by local changes in capacitance. In order to effectively operate without false inputs, the raw capacitive signals are heavily processed to subtract noise and properly identify single and multiple touches. It has been shown that the capacitance interface itself is compatible with sensitive chemical detection, such as was demonstrated in by Won and Park, 2012, where the capacitive interface can resolve changes in the pF range, and was demonstrated for DNA detection between 10 and $100 \mathrm{ng} \mu \mathrm{L}^{-1}$. This attractive possibility was demonstrated with a touch screen kit, where the entire capacitance sensitivity is directly accessible; however, in order to be suitable with ADDCA, it has yet to be shown to be possible on an actual cell phone. In phones, only the detected touch screen coordinates are accessible from the regular operating system 
resources, which is the result of the touch identification processing. Deeper access to the raw capacitance, if feasible, would most probably require software tailored to each hardware configuration, which essentially defeats the purpose of ADDCA solutions.

Despite of these inconveniencies, touch screen interfaces offer a large area for potentially multiple detections and a simple readout if the signals could be transduced as touch coordinates. Phone screens are also continuously increasing their screen resolution, and solutions such as the V-chip have the potential to exploit screen coordinates readout if the response columns could be capacitively coupled to the screen.

The concepts discussed in this work cover those most suitable for implementation as cell phone complementary disposables, whether they have already been demonstrated or because of their prowess and potential to be implemented in the ADDCA context. Unfortunately, this selection leaves aside elegant and inspiring concepts such as digital microfluidics (Choi et al., 2012) and universal coupling through hands-free phone protocols (Nemiroski et al., 2014), since they demand electronic interfacing and are more suitable with reusable dongles, even if they can incorporate disposable components.

\section{Conclusions}

Cell phones are powerful devices that can supply the role of computers in computer-controlled instruments. Such alternative offers total freedom to design biosensing instrumentation for dedicated POC purposes, but cancels the ubiquity of cell phones.

At the other extreme, solutions focused on entirely retaining cell phone ubiquity are emerging. This can be seen as the result of two convergent trends: the development of autonomous LOC devices and the sophistication and widespread availability of cell phones. In their present form, cell phones integrate numerous physical sensors and computer capabilities that hold a residual capacity to be repurposed for chemical sensing, biosensing, and diagnostics if matched with proper complementary devices.

It is tempting to believe that cell phones will in the future incorporate chemical sensors and biosensors in the same way as the diverse physical sensors of today; however, the equivalent to these physical sensors implies single partially selective and reusable sensors, which are incompatible with the multivocal type of stimuli in chemical sensing and diagnostics, let alone the dedicated sample conditioning requirements.

Modular phone designs (http://www.projectara.com; https://phonebloks.com/en) could be a niche for chemical sensing support but not necessarily the most popular consumer choice, which is the 
central aspect behind cell phone ubiquity and the rationale for using phones in their default configuration, and without permanent accessories, for biosensing.

ADDCA offers a strategy to adapt and capitalize on the autonomous LOC toolbox to best exploit current cell phone resources and those that can be expected in future generations.

Within this context, it becomes evident that popular detection approaches such as color and intensity responses are not the most convenient for cell phone readout and that there are better alternatives to be exploited.

The evolution of phone platforms has provided them with cameras that have improved mainly in terms of pixel count, acquisition frame rate and dynamic range rather than in intensity and color resolution. Accordingly, the transduction mechanisms that exploit these aspects are best positioned to fully capitalize on the potential of cell phone cameras for readout.

Thus, principles such as SPR, SlipChip/SlipPAD and their digitally coded responses, V-chips, timediffusion responses, kinetic responses and any other form of spatially distributed response are the most advantageous for exploiting the phone resources.

In addition, spatially distributed or coded responses as well as time responses that are not exclusively quantified by intensity are robust to ubiquitous illuminating conditions, which allows for the important simplification of using uncontrolled ambient illumination.

The surveyed plausible and demonstrated implementations suggest that beyond the necessary conversions, advanced performance and ambitious detection targets could be materialized based on ubiquitous disposables complementing cell phone readout. In order to be candidates for clinical use, the overall performance of these devices will have to gauge not only precision but also reproducibility, long-term storage capabilities and strict validation against established methods.

From the self-powered and passive autonomous principles surveyed here, many solutions can be directly exploited to provide autonomous operation on cell phones. In some cases, the involved fabrication and required resources are demanding, but the central aspects of these inspiring concepts are robust enough to undergo their adaptation as universal devices for cell phone biosensing.

\section{Acknowledgments}

This work was supported by grants to D.F. from the Swedish Research Council (VR) and the Carl Tryggers Foundation. 
Figure captions

Figure 1. Conceptual schematics of an autonomous disposable device for cell phone analyses (ADDCA). The autonomous device includes sample extraction/collection elements, a self-powered mechanism for transport, sample preparation, calibration range generation ( $\mathrm{L}$, and $\mathrm{H}$ represent the low and high concentrations of the calibration range, and $S$ the unknown sample concentration) and a chemical response configured to best exploit cell phone camera readout resources. The ADDCA also integrates the universal coupling element, in this case for optical readout, to any phone camera using a single device architecture.

Figure 2a) Blood extraction device that encapsulates a vacuum pouch with a sealed micro-needle reproduced from ( $\mathrm{Li}$ et al., 2015) with permission form the Royal Society of Chemistry. b) 3D printed lid actuated finger pump configured for suction, reproduced from (Begolo et al., 2014) with permission form the Royal Society of Chemistry. c) 3D printed unibody-LOC finger pump combining a silicone tubing (not in the figure) and a PDMS unidirectional valve, from (Comina et al., 2015a) Copyright Wiley-VCH Verlag GmbH \& Co. KGaA. Reproduced with permission. d) Albumin testing in urine using a reusable instrument for cell phone readout, reproduced from (Coskun et al., 2013) with permission form the Royal Society of Chemistry. e) Typical configuration of a commercial lateral flow immunoassay. f) Four ways circulation in three-dimensional paper fluidics, from (Martinez et al., 2008b). Copyright (2008) National Academy of Sciences, U.S.A.

Figure 3a) Plasma separation using red blood cells retention within a trench, reproduced from (Dimov et al., 2011) with permission from the Royal Society of Chemistry. b) Ratchet geometry for particles concentration, reproduced from (Park et al., 2012) with permission form the Royal Society of Chemistry. c) Flow based separation of plasma from erythrocytes, and spatially distributed hematocrit embedded readout with ELISA detection sector, reproduced from (Browne et al., 2011) with permission form the Royal Society of Chemistry. d) PCR amplification device with static temperature gradient for thermal cycling and spatially distributed readout that allows simultaneous cycle-dependent fluorescence and temperature-dependent fluorescence acquisition, reproduced from (Pjescic and Crews, 2012) with permission form the Royal Society of Chemistry. e) Modular assembly of primer section for multi-target, multi-sample PCR amplification and detection, edited from (Manage et al., 2013) with permission form the Royal Society of Chemistry. f) Lateral flow immunoassay for the detection of dengue-specific immunoglobulins in salivary fluid, reproduced from (Zhang et al., 2015) with permission form the Royal Society of Chemistry. g) Cell-free synthetic gene network detection principle, reproduced from (Pardee et al., 2014). With permission from Elsevier Limited. 
Figure 4a) Lateral flow device configured for programmed sequential substance transport, reproduced from (Lutz et al., 2011) with permission form the Royal Society of Chemistry. b) Selfpowered auxiliary fluid suction device, reproduced from (Kokalj et al., 2014) with permission form the Royal Society of Chemistry. c) Self-powered hybrid chip for multiplexed protein assays from whole blood, reproduced from (Qin et al., 2009) with permission form the Royal Society of Chemistry. d) Phaseguide controlled flow concept, reproduced from (Vulto et al., 2011) with permission form the Royal Society of Chemistry. e) SlipChip device showing simultaneous sample filling and exposure steps, reproduced from (Du et al., 2009) with permission form the Royal Society of Chemistry. f) Self-powered devices using oxygen that is generated by the introduction of a Pt/Ag pin into hydrogen peroxide solution, reproduced from (Wang et al., 2010) with permission form the Royal Society of Chemistry. g) Finger pump in classical LOC technology, reproduced from (Iwai et al., 2014) with permission form the Royal Society of Chemistry. h) 3D printer ULOC device with finger pump and $3 D$ printed optics, where $H$ and $L$ are the high and low calibration concentrations and $\mathrm{S}$ the sample concentration, from (Comina et al., 2015a). Copyright Wiley-VCH Verlag GmbH \& Co. KGaA. Reproduced with permission.

Figure 5a) Disposable optical coupler for angle resolved SPR detection on cell phones, from (Preechaburana et al., 2012a) Copyright Wiley-VCH Verlag GmbH \& Co. KGaA. Reproduced with permission. b) Time-diffusion recording principle, reproduced from (Gerber et al., 2014) with permission form the Royal Society of Chemistry. c) V-chip concept showing a SlipChip configuration with self-powered displacement of an ink column for readout, from (Song et al., 2012). Image reprinted with permission from Macmillan Publishers Ltd: Nature Communications, Copyright 2012. d) Time resolved readout of sample and calibration range for ambient illuminated detection on cell phones, where $\mathrm{H}$ and $\mathrm{L}$ are the high and low calibration concentrations, $\mathrm{S}$ the sample concentration, and $r_{1}$ and $r_{2}$ are assay reagents, from (Comina et al., 2015b). Copyright Wiley-VCH Verlag GmbH \& Co. KGaA. Reproduced with permission. e) Near field communication (NFC) gas sensing using disposable tags interfaced to a cell phone, from (Azzarelli et al., 2014). Copyright (2014) National Academy of Sciences, U.S.A. 


\section{References}

Abgrall P, Gué AM. J. Micromech. Microeng. 2007;17:R15-R49.

Addae-Mensah KA, Cheung JK, Fekete V, Rendely MS, Sia SK. Lab Chip 2010;10:1618-1622.

Ahn $\mathrm{CH}$, Choi J, Beaucage G, Nevin JH, Lee J, Puntambekar A, Lee JY. Proceedings of the IEEE 2004;92;154-173.

Azzarelli JM, Mirica KA, Ravnsbæk JB, Swager TM. PNAS 2014;111:18162-18166.

Bartholomeusz D, Boutt R, Andrade J. J. Microelectromech. Syst. 2005;14:1364-1374.

Bartlett JMS, Stirling D, Eds. PCR Protocols in Methods in Molecular Biology ${ }^{\mathrm{TM}}$, Volume 226, 2003, Humana Press, Totowa, New Jersey.

Begolo S, Zhukov DV, Selck DA, Lib L, Ismagilov RF. Lab Chip 2014;14:4616-4628.

Beltzer EK, Fortunato CK, Guaderrama MM, Peckins MK, Garramone BM, Granger DA. Physiol Behav 2010;101(2):289-296.

Bharadwaj R, Singh A. Autonomous Lab-on-a-Chip Technologies, in Autonomous Sensor Networks:

Collective Sensing Strategies for Analytical Purposes. Ed. Filippini D, Springer Series on Chemical Sensors and Biosensors (Series Ed. Urban G), Volume 13, 2013, 217-236.

Bhattacharyya A, Klapperich CM. Anal Chem 2006;78:788-792.

Breslauer DN, Maamari RN, Switz NA, Lam WA, Fletcher DA. PLoS ONE 2009;4:e6320.

Brown RB, Audet J. J R Soc Interface 2008;5(Suppl 2):131-138.

Browne AW, Ramasamy L, Cripec TP, Ahn CH. Lab Chip 2011;11:2440-2446.

Byrnes S, Thiessen G, Fu E. Bioanalysis 2013;5:2821-2836.

Chen H, Cogswell J, Anagnostopoulos C, Faghri M. Lab Chip 2012;12,2909-2913.

Chen H, Cogswell J, Anagnostopoulos C, Faghri M. Lab Chip 2012;12:2909-2913.

Chin CD, Linder V, Sia SK. Lab Chip 2012;12:2118-2134.

Choi K, Ng AHC, Fobel R, Wheeler AR. Annu. Rev. Anal. Chem. 2012;5:413-440.

Chou J, Wong J, Christodoulides N, Floriano PN, Sanchez X, McDevitt J. Sensors 2012;12;15467-15499.

Christodoulides N, Mohanty S, Miller CS, Langu MC, Floriano PN, Dharshan P, Ali MF, Bernard B,

Romanovicz D, Anslyn E, Fox PC, McDevitt JT. Lab Chip 2005;5:261-269.

Comina G, Suska A, Filippini A. Angewandte Chemie 2015;54:8708 -8712. (a)

Comina G, Suska A, Filippini D. Micromachines 2015;6:437-451. (b)

Comina G, Suska A, Filippini D. Lab Chip 2014;14:2978-2982. (a)

Comina G, Suska A, Filippini D. Lab Chip 2014;14:424-430. (b)

Coskun AF, Nagi R, Sadeghi K, Phillips S, Ozcan A. Lab Chip 2013;13:4231-4238.

Crevillé AG, Hervás M, López MA, González MC, Escarpa A. Talanta 2007;74:342-357.

D’Ambrosio MV, Bakalar M, Bennuru S, Reber C, Skandarajah A, Nilsson L, Switz N, Kamgno J, Pion S,

Boussinesq M, Nutman TB, Fletcher DA. Science Translational Medicine 2015;7:286re4,1-8.

Dewsnap CH, Mcowan A. Int J STD AIDS 2006;17:357-359.

Di Carlo D, Jeong KH, Lee LP. Lab Chip 2003;3:287-291.

Dimov IK, Basabe-Desmonts L, Garcia-Cordero JL, Ross BM, Ricco AJ, Lee LP. Lab Chip 2011;11:845-850.

Du W, Li L, Nichols KP, Ismagilov RF. SlipChip. Lab Chip 2009;9:2286-2292.

Ducrée J, Haeberle S, Lutz S, Pausch S, von Stetten F, Zengerle R. J. Micromech. Microeng. 2007;17:S103S115.

Durner J. Angew. Chem. Int. Ed. 2010;49:1026 - 1051. 
Fan R, Vermesh O, Srivastava A, Yen BKH, Qin L, Ahmad H, Kwong GA, Liu CC, Gould J, Hood L, Heath JR. Nat. Biotechnol. 2008;26:1373-1378.

Filippini D, Lundström I. Analyst 2006;131:111-117.

Filippini D, Lundström I. Analytica chimica acta 2004;521:237-244.

Floris A, Staal S, Lenk S, Staijen E, Kohlheyer D, Eijkel J, van den Berg A. Lab Chip 2010;10:1799-1806.

Ganesan AV, Kumar H, Swaminathan S, Singh KK, Joy RA, Sood N, Gokhale T, Mittal RK. Bionanoscience 2014;4:128-135.

Gattiker GE, Kaler KV, Mintchev MP. Microsyst. Technol. 2005;12:44-51.

Gerber LC, Rosenfeld L, Chen Y, Tang SKY. Lab Chip 2014;14:4324-4328.

Gervais L, de Rooij N, Delamarche E. Adv. Healthcare Mater. 2011;23:H151-H176.

Gervais L, Delamarche E. Lab Chip 2009;9:3330-3337.

Global mobile statistics 2014 Part A: Mobile subscribers; handset market share; mobile operators, http://mobiforge.com/research-analysis/global-mobile-statistics-2014-part-a-mobile-subscribers-handsetmarket-share-mobile-operators, accessed 25/05/15

Gubala V, Harris LF, Ricco AJ, Tan MX, Williams DE. Anal. Chem. 2012;84:487-515 .

Haeberle S, Brenner T, Zengerle R, Ducree J. Lab Chip 2006;6:776-781.

Hakenberg S, Hügle M, Weidmann M, Hufert F, Dame G, Urban GA. Lab Chip 2012;12:4576-4580.

Hatch AV, Herr AE, Throckmorton DJ, Brennan JS, Singh AK. Anal. Chem. 2006;78:4976-4984.

Herr AE, Hatch AV, Throckmorton DJ, Tran HM, Brennan JS, Giannobile WV, Singh AK. PNAS 2007;104:5268-5273.

Homola J. Chem. Rev. 2008;108:462-493.

Hosokawa K, Sato K, Ichikawa N, Maeda M. Lab Chip 2004;4:181-185.

Hosokawa K, Sato K, Ichikawa N, Maeda M. Lab Chip 2006;6:236-241.

Hou HW, Bhagat AAS, Lee WC, Huang S, Han J, Lim CT. Micromachines 2011;2:319-343.

http://holomic.com (accessed 17.08.2015).

http://uk.clearblue.com/clearblue-pregnancy-tests-range; http://www.firstresponse.com/early-pregnancy-test; http://www.eptfamily.com/products/ept ${ }^{\mathrm{TM}}$-pregnancy-test; (Accessed 2.6.15)

http://www.projectara.com; https://phonebloks.com/en; (accessed 6.8.15).

https://github.com/ytai/ioio/wiki (accessed 20.08.15).

https://www.accu-chek.co.uk/gb/products/fingerprickers/index.html (accessed 01.06.15); http://www.lifescan.co.uk/ourproducts/accessories/lancingdevice (accessed 01.06.15);

https://www.apple.com/iphone/compare/; http://www.samsung.com/us/explore/galaxy-s-6-features-andspecs/ (accessed 21.06.15)

https://www.cobasliat.com (accessed 17.08.2015).

Huang B, Wu H, Bhaya D, Grossman A, Granier S, Kobilka BK, Zare RN. Science 2007;315:81-84.

Inglis DW, Riehn R, Austin RH, Sturm JC. Appl Phys Lett 2004;85:5093-5095.

Iwai K, Shih KC, Lin X, Brubaker TA, Sochol RD, Lin L. Lab Chip 2014;14:3790-3799.

Jobling M, Pandya A, Tyler-Smith C. Int. J. Leg. Med. 1997;110:118-124.

Kermekchiev MB, Kirilova LI, Vail EE, Barnes WM. Nucl. Acids Res. 2009;37:e40-e54.

Kersaudy-Kerhoas M, Sollier E. Lab Chip 2013;13:3323-3346.

Khanna P, Strom JA, Malone JI, Bhansali S. J Diabetes Sci Technol 2008;2:1122-1129.

King D, O’Sullivan M, Ducrée J. Journal of Modern Optics 2014;61:85-101.

Kitson PJ, Rosnes MH, Sans V, Dragone V, Cronin L. Lab Chip 2012;12:3267-3271. 
Kokalj T, Park Y, Vencelj M, Jenko M, Lee LP. Lab Chip 2014;14:4329-4333.

Kondapalli S, Connelly JT, Baeumner AJ, Kirby BJ. Microfluid Nanofluid 2011;11:537-544.

Kovarik ML, Gach PC, Ornoff DM, Wang Y, Balowski J, Farrag L, Allbritton NL. Anal. Chem. 2012;84:516540.

Kutter JP, Jacobson SC, Ramsey JM. J Microcolumn 2000;Sep. 12: 93-97.

Laksanasopin T, Guo TW, Nayak S, Sridhara AA, Xie S, Olowookere OO, Cadinu P, Meng F, Chee NH, Kim J, Chin CD, Munyazesa E, Mugwaneza P, Rai AJ, Mugisha V, Castro AR, Steinmiller D, Linder V, Justman JE, Nsanzimana S, Sia SK. Science Translational Medicine 2015;7:273re1,1-9.

Lauks IR. Acc. Chem. Res. 1998;31:317-324.

Li CG, Dangol M, Lee CY, Jang M, Jung H. Lab Chip 2015;15: 382-390.

Li J, Yu G, Lu Y, Hsiung C, Hannon A, Kim D. IEEE Sensors Conference, Taipei, October 28-31, 2012.

Lien KY, Lin W, Lee Y, Wang C, Lei H, Lee G. J. Microelectromech Syst 2008;17:288-301.

Lim YC, Kouzani AZ, Duan W. Microsyst. Technol. 2010;16:1995-2015.

Liu G, Shen C, Yang Z, Cai X, Zhang H. Sens. Actuators A 2010;163: 291-296. (a)

Liu H, Li X, Crooks RM. Anal. Chem. 2013;85:4263-4267.

Liu W, Chen D, Du W, Nichols KP, Ismagilov RF. Anal. Chem. 2010;82:3276-3282. (b)

Love JC, Wolfe DB, Jacobs HO, Whitesides GM. Langmuir 2001;17:6005-6012.

Luppa PB, Müller C, Schlichtiger A, Schlebusch H. Trends in Analytical Chemistry 2011;30:887-898.

Lutz B, Liang T, Fu E, Ramachandran S, Kauffman P, Yager P. Lab Chip 2013;13:2840-2847.

Lutz BR, Trinh P, Ball C, Fu E, Yager P. Lab Chip 2011;11:4274-4278.

Macken S, Lundström I, Filippini D. Applied physics letters 2006;89:254104.

Madou MJ, Lee LJ, Daunert S, Lai S, Shih C. Biomedical Microdevices 2001;3:245-254.

Mair DA, Schwei TR, Dinio TS, Svec F, Fréchet JMJ. Lab Chip 2009;9:877-883.

Malik MA, Gatto E, Macken S, DiNatale C, Paolesse R, D’Amico A, Lundström I, Filippini D. Analytica chimica acta 2009;635:196-201.

Manage DP, Lauzon J, Atrazev A, Chavali R, Samuel RA, Chan B, Morrissey YC, Gordy W, Edwards AL, Larison K, Yanow SK, Acker JP, Zahariadis G, Pilarski LM. Lab Chip 2013;13:2576-2584.

Mariella R. Biomed Microdevices 2008;10:777-784.

Martel JM, Smith KC, Dlamini M, Pletcher K, Yang J, Karabacak M, Haber DA, Kapur R, Toner M. Scientific Reports 2015;5:11300-113012.

Martinez A, Phillips S, Carrilho E, Thomas S, Sindi H, Whitesides G. Anal Chem 2008;80:3699-3707. (a)

Martinez AW, Phillips ST, Nie Z, Cheng C, Carrilho E, Wiley BJ, Whitesides GM. Programmable diagnostic devices made from paper and tape. Lab Chip 2010;10:2499-2504.

Martinez AW, Phillips ST, Whitesides GM. PNAS 2008;105:19606-19611. (b)

Matson RS. 2008. Microarray Methods and Protocols. Boca Raton, Florida: CRC.

Mello AJ, Beard N. Lab Chip 2003;3:11N-20N.

Mohamed R, Campbell J, Cooper-White J, Dimeski G, Punyadeera C. Clinical and Translational Medicine 2012;1:19; doi:10.1186/2001-1326-1-19.

Mudanyali O, Dimitrov S, Sikora U, Padmanabhan S, Navruz I, Ozcan A. Lab Chip 2012;12;2678-2686.

Nemiroski A, Christodouleas DC, Hennek JW, Kumar AA, Maxwell EJ, Fernández-Abedul MT, Whitesides GM. PNAS 2014;111:11984-11989.

Nguyen LH, Moheb S. US Pat. 6,372, 513, 2001.

Nisar A, Afzulpurkar N, Mahaisavariya B, Tuantranont A. Sens. Actuators B 2008;130:917-942. 
Noh H, Phillips ST. Chem., 2010;82(19):8071-8078.

Ocvirk G, Salimi-Moosavi H, Szarka RJ, Arriaga EA, Andersson PE, Smith R, Dovichi NJ, Harrison DJ. Proc. IEEE 2004;92:115-125.

Osborn JL, Lutz B, Fu E, Kauffman P, Stevens DY, Yager P. Lab Chip 2010;10:2659-2665.

Pardee K, Green AA, Ferrante T, Cameron DE, DaleyKeyser A, Yin P, Collins JJ. Cell 2014; http://dx.doi.org/10.1016/ j.cell.2014.10.004

Park S, Hong X, Choi WS, Kim T. Lab Chip 2012;12;3914-3922.

Pjescic I, Crews N. Lab Chip 2012;12:2514-2519.

Pjescic I, Tranter C, Hindmarsh P, Crews N. Biomed. Microdevices 2010;12:333-343.

Potyrailo R. Ubiquitous Devices for Chemical Sensing, in Autonomous Sensor Networks: Collective Sensing Strategies for Analytical Purposes, Ed. Filippini D, Springer Series on Chemical Sensors and Biosensors (Series Ed. Urban G), Volume 13, 2013, pp. 237-264.

Preechaburana P, Collado Gonzalez M, Suska A, Filippini D. Angew. Chem. Int. Ed. 2012;51:11585-11588. (a)

Preechaburana P, Filippini D. Lab on a Chip 2011;11:288-295. (a)

Preechaburana P, Macken S, Suska A, Filippini D. Biosensors and Bioelectronics 2011;26:2107-2113. (b)

Preechaburana P, Suska A, Filippini D. Trends in Biotechnlogy 2014;32:351-355.

Preechaburana P, Suska A, Filippini D. Sensors 2012;12:8586-8600. (b)

Preechaburana $P$, Suska A, Filippini D. Interfacing diagnostics with consumer electronics, in Mobile Point-ofCare Monitors and Diagnostic Device Design. Eds. Iniewsky K, Karlen W. CRC Press, Boca Raton, 2015, Ch. 1, 3-22.

ProteoSpinTM Urine Protein Concentration Micro Kit. @ 2014 Norgen Biotek Corp; SigmaPrepTM Spin Columns, Catalog Number SC1000, sigma-aldrich.com.

Qin L, Vermesh O, Shi Q, Heath JR. Lab Chip 2009;9:2016-2020.

Qiu X, Thompson JA, Chen Z, Liu C, Chen D, Ramprasad S, Mauk MG, Ongagna S, Barber C, Abrams WR, Malamud D, Corstjens PLAM, Bau HH. Biomed Microdevices 2009;11:1175-1186.

Ray S, Britschgi M, Herbert C, Takeda-Uchimura Y, Boxer A, Blennow K, Friedman LF, Galasko DR, Jutel M, Karydas A, Kaye JA, Leszek J, Miller BL, Minthon L, Quinn JF, Rabinovici GD, Robinson WH, Sabbagh MN, So YT, Sparks DL, Tabaton M, Tinklenberg J, Yesavage JA, Tibshirani R, Wyss-Coray T. Nat. Med. 2007;13:1359-1362.

Reinhard E, Ward G, Pattanaik S, Debevec P, Heidrich W, Myszkowsky K. High dynamic range imaging. Acquisition, display and image-based lighting, Morgan Kaufmann Publishers - Elsevier, 2010.

Safavieha R, Juncker D. Lab Chip 2013;13:4180-4189.

Saltman RB, Bankauskaite V, Vrangbaek K, Eds., Decentralization in health care, European Observatory on Health Systems and Policies Series, McGraw Hill - Open University Press, Maidenhead, 2007.

Schasfoort RBM, Tudos AJ. Handbook of Surface Plasmon Resonance, The Royal Society of Chemistry, Cambridge, 2008.

Sen-Yung H, Ren-Kung C, Yi-Hsin P, Hai-Lun L. Proteomics 2006;6:3189-3198.

Shallan AI, Smejkal P, Corban M, Guijt RM, Breadmore MC. Anal. Chem. 2014;86:3124-3130.

Shen F, Du W, Kreutz JE, Fok A, Ismagilov RF. Lab Chip 2010;10:2666-2672.

Shim JS, Browne AW, Ahn CH. Biomed. Microdevices 2010;12:949-957.

Sin MLY, Gao J, Liao JC, Wong PK. Journal of Biological Engineering 2011;5/6: 1-21.

Smith MT, Wilding KM, Hunt JM, Bennett AM, Bundy BC. FEBS Letters 2014;588:2755-2761.

Smith ZJ, Chu K, Espenson AR, Rahimzadeh M, Gryshuk A, Molinaro M, Dwyre DM, Lane S, Matthews D, Wachsmann-Hogiu S. PLoS ONE 2011;6:e17150. 
Song Y, Zhang Y, Bernard PE, Reuben JM, Ueno NT, Arlinghaus RB, Zu Y, Qin L. Nature Communications 2012;3;1283.

Sun C, Fang N, Wu DM, Zhang X. Sensors and Actuators A: Physical 2005;121:113-120.

Switz NA, D’Ambrosio MV, Fletcher DA. PLoS ONE 2014;9:e95330.

Symes MD, Kitson PJ, Yan J, Richmond CJ, Cooper GJT, Bowman RW, Vilbrandt T, Cronin L. Nat Chemistry 2012;4:349-354.

The World Population Situation in 2014. A Concise Report, Department of Economic and Social Affairs Population Division, ST/ESA/SER.A/354, United Nations, New York, 2014.

Tropea S, Brengi D, Hernandez A, Alamon D, Parra M, Longinotti G, Ybarra G, Lloret P, Mass M, Roberti M, Lloret M, Malatto L, Moina C, Fraigi L, Melli L, Cortina ME, Serantes DR, Ugalde JE, Ciocchini A, Comerci DJ. Smartphone controlled platform for point-of-care diagnosis of infectious diseases, 2014 IEEE 9th IberoAmerican Congress on Sensors, 10.1109/IBERSENSOR.2014.6995525.

Tseng P, Murray C, Kim D, Di Carlo D. LabChip 2014;14:1491-1495.

Tumbleston JR, Shirvanyants D, Ermoshkin N, Janusziewicz R, Johnson AR, Kelly D, Chen K, Pinschmidt R, Rolland JP, Ermoshkin A, Samulski ET, DeSimone JM. Science 2015;347:1349-1352.

VanDelinder V, Groisman A. Anal. Chem. 2006;78:3765-3771.

Vashist SK, Mudanyali O, Schneider EM, Zengerle R, Ozcan A. Anal Bioanal Chem 2014;406:3263-3277.

Venge P, Ohberg C, Flodin M, Lindahl B. Am. Heart J. 2010;160:835-841.

Vulto P, Podszun S, Meyer P, Hermann C, Manz A, Urban GA. Lab Chip 2011;11:1596-1602.

Waldbaur A, Rapp H, Länge K, Rapp BE. Anal. Methods 2011;3:2681-2716.

Wang J, Ahmad H, Ma C, Shi Q, Vermesh O, Vermesh U, Heath J. Lab Chip 2010;10:3157-3162.

Wang X, Guo Q, Cai X, Zhou S, Kobe B, Yang J. ACS Appl. Mater. Interfaces 2014;6:2583-2587.

Westland S, Ripamonti C. Computational Colour Science, Wiley, 2004.

Wie Q, Luo W, Chiang S, Kappel T, Mejia C, Tseng D, Chan RYL, Yan E, Qi H, Shabbir F, Ozkan H, Feng A, Ozcan A. ACS Nano 2014;8:2725-12733.

Wie Q, Qi H, Luo W, Tseng D, Ki SK, Wan Z, Göröcs Z, Bentolila LA, Wu T, Sun R, Ozcan A. ACS Nano 2013;7:9147-9155.

Wittwer CT, Reed GB, Ririe KM. in Rapid Cycle DNA, Amplification, Ed. Mullis KB, Ferre F, Gibbs R. Springer-Verlag, Deerfield Beach, 1994, pp. 174-181.

Won BY, Park HG. Angew. Chem. Int. Ed. 2012;51:748 -751.

Wong RC, Tse HY. Eds.. Lateral Flow Immunoassay, Humana Press, c/o Springer Science+Business Media, New York, USA, 2009.

Wyszecki G, Stiles W. Color Science: Concepts and Methods, Quantitative Data and Formulae, Wiley, New York, 1982.

Yang S, Undar A, Zahn JD. Lab Chip 2006;6:871-880.

Yetisen AK, Akram MS, Lowe CR. Lab Chip 2013;13:2210-2251.

Zelin J, Garrett N, Saunders J, Warburton F, Anderson J, Moir K, Symonds M, Estcourt C. North East London Sexual Health Network Research Consortium. Int J STD AIDS 2008;19:665-667.

Zhang C, Xing D. Nucleic Acids Research 2007;35:4223-4237.

Zhang Y, Bai J, Ying JY. Lab Chip 2015;15:1465-1471.

Zhu H, Isikman SO, Mudanyali O, Greenbaum A, Ozcan A. Lab Chip 2013;13:51-67.

Zimmermann M, Schmid H, Hunziker P, Delamarche E. Lab Chip 2007;7:119-125. 
Fig. I

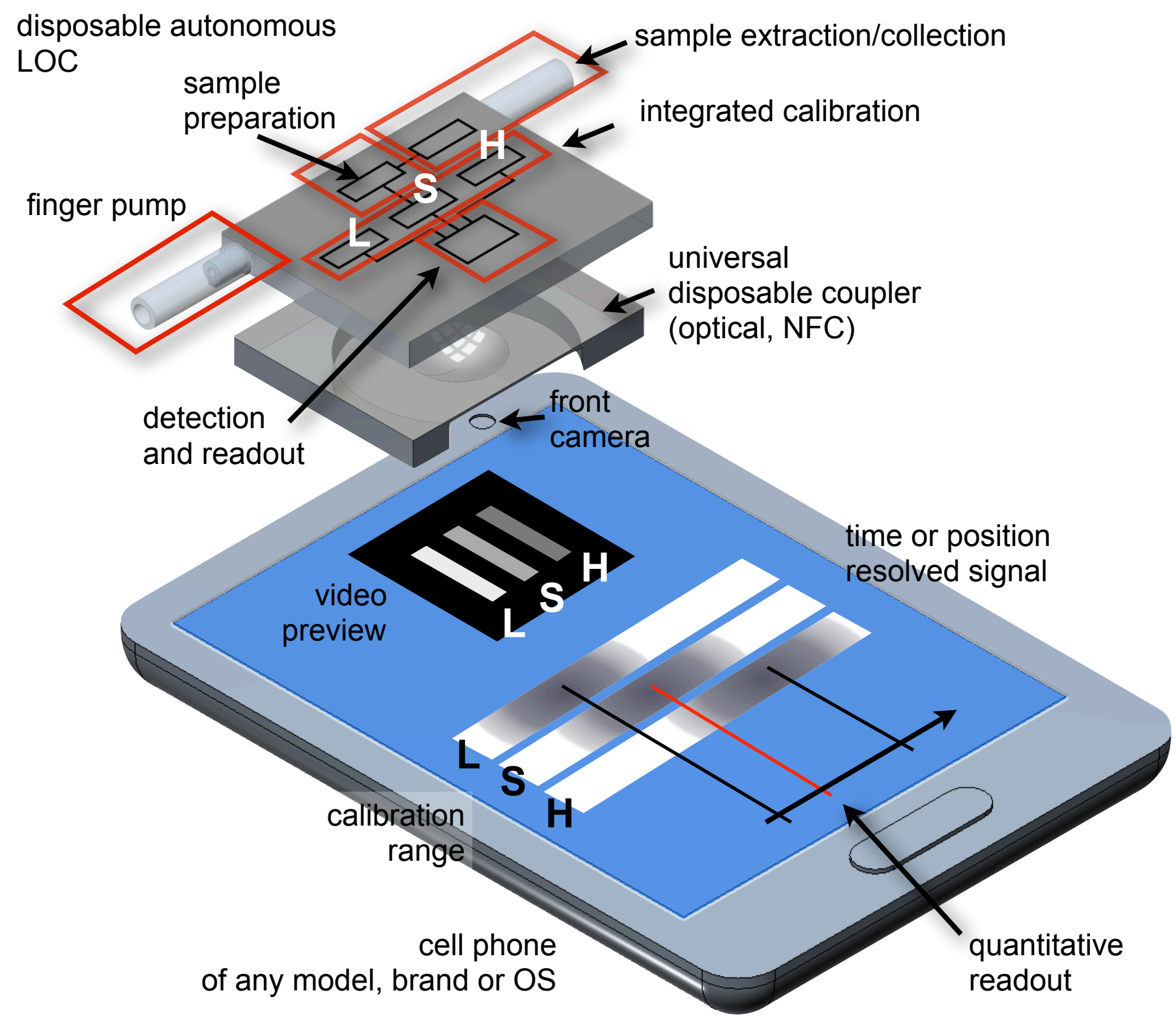


(a)
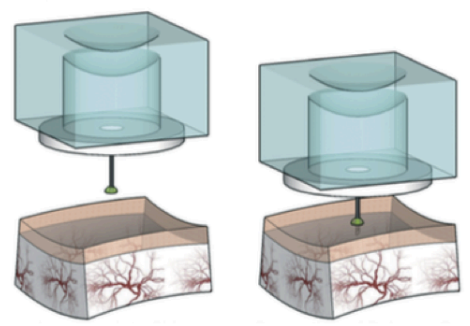

Fig.2
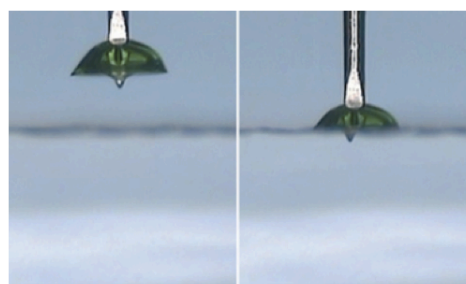

(b)

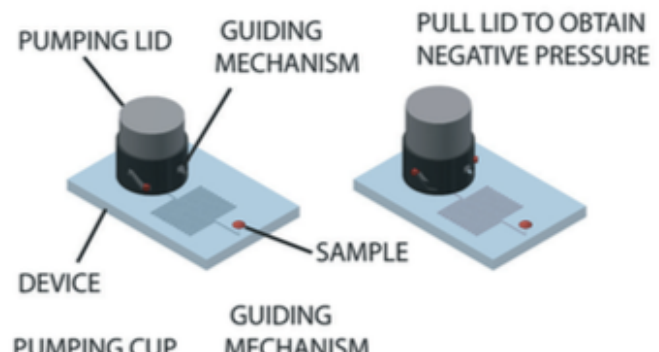

PUMPING CUP MECHANISM
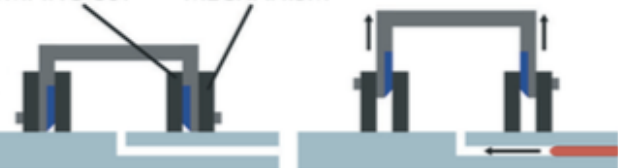

(c)

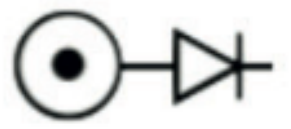

connector to tubing

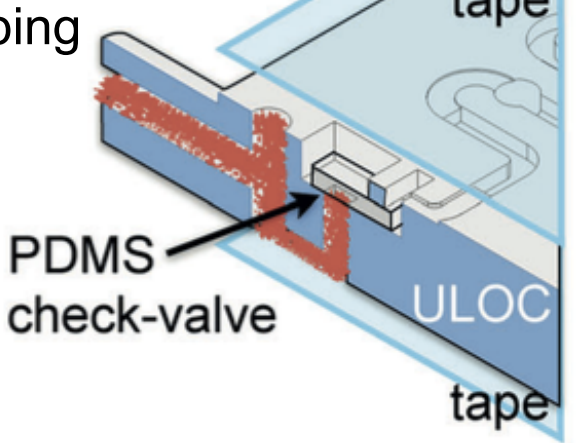

(d)
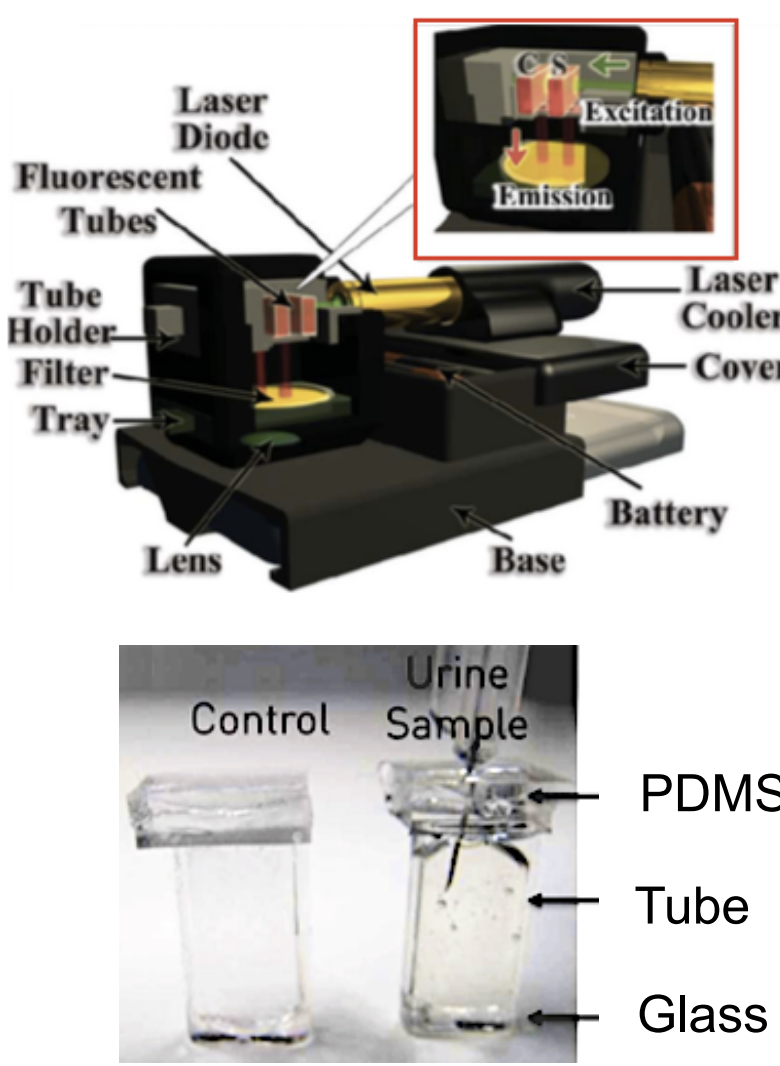

(e) sample pad result window

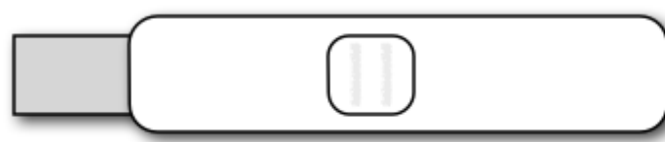

pregnant not pregnant

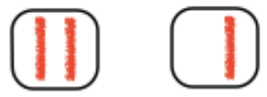

(f)

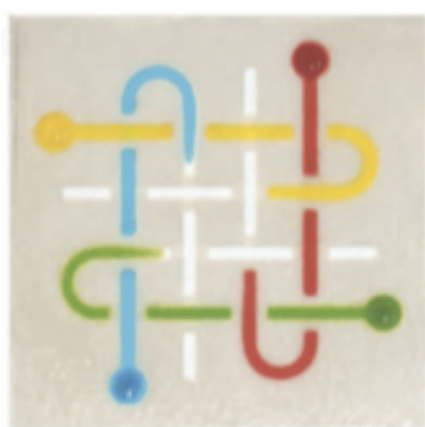


(a)

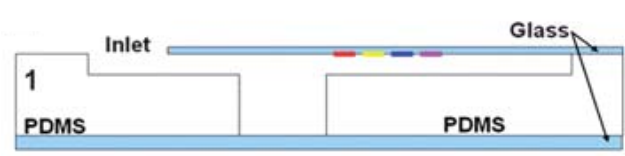

\begin{tabular}{|l|}
\hline Vacuum Packaging \\
\hline 2 \\
PDMS
\end{tabular}
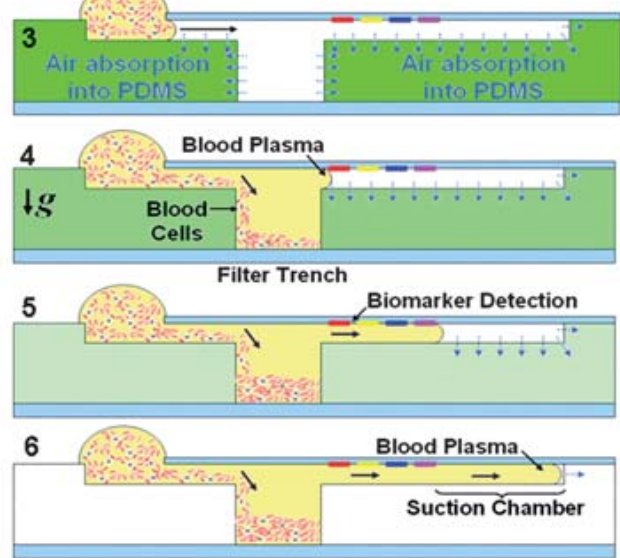

(b)

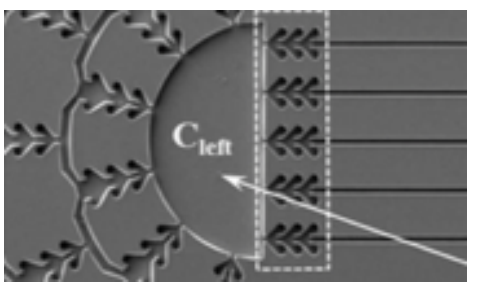

(f)

(c)

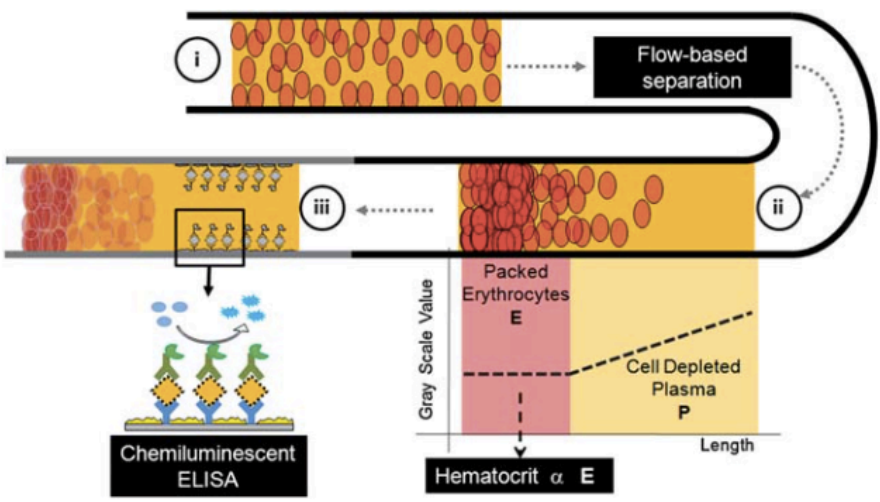

(d)

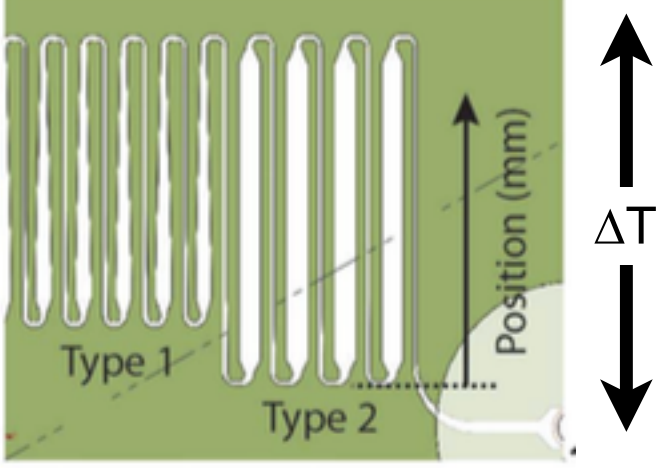

(e)
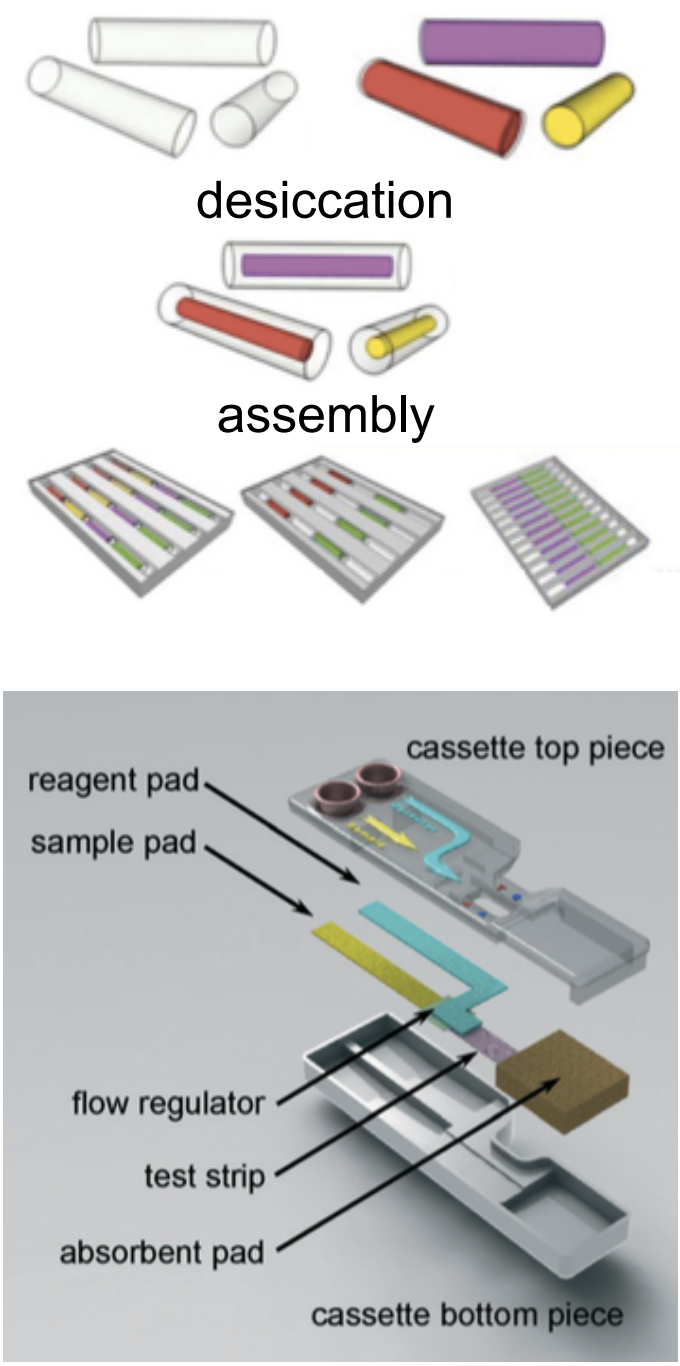

(g)
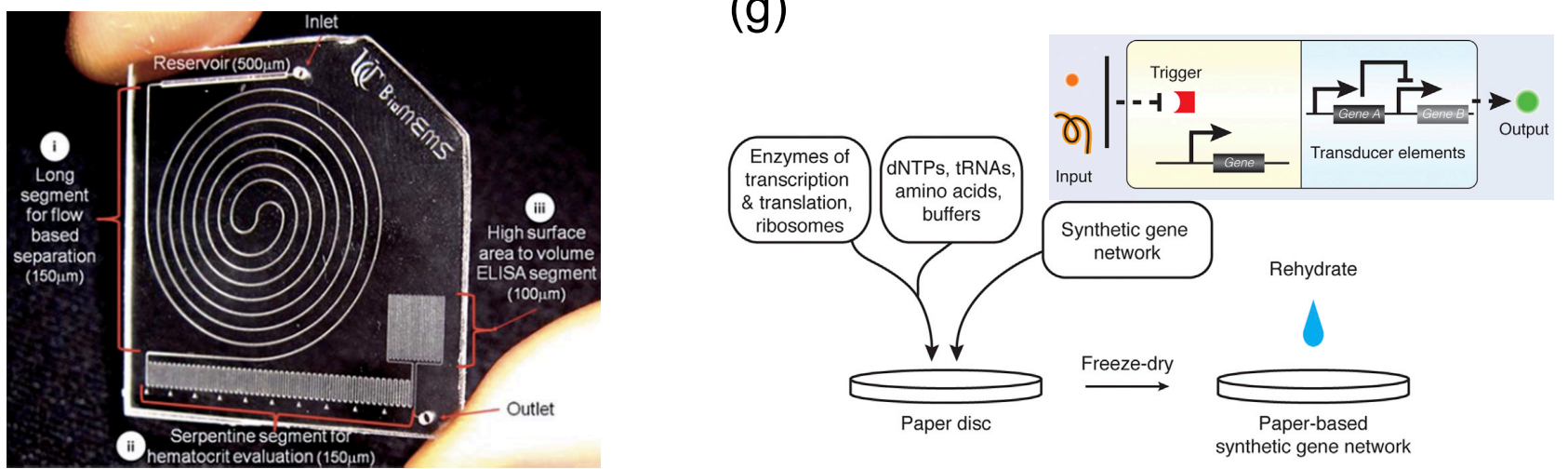
(a)
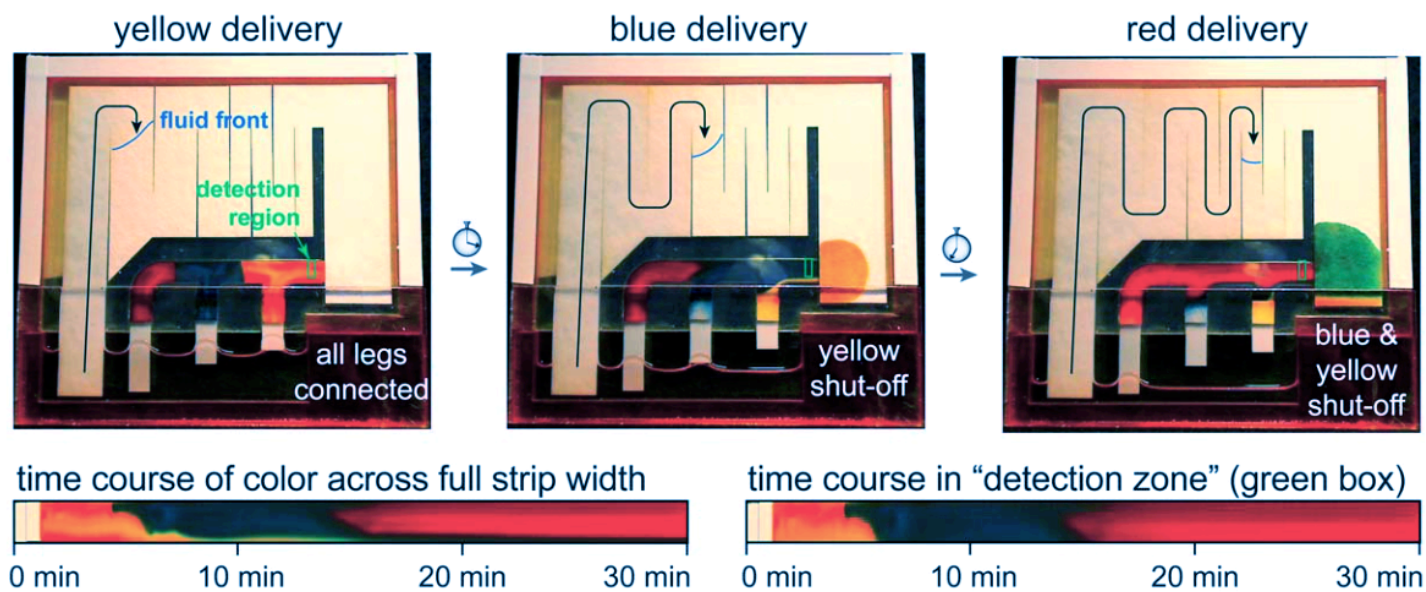

(b)

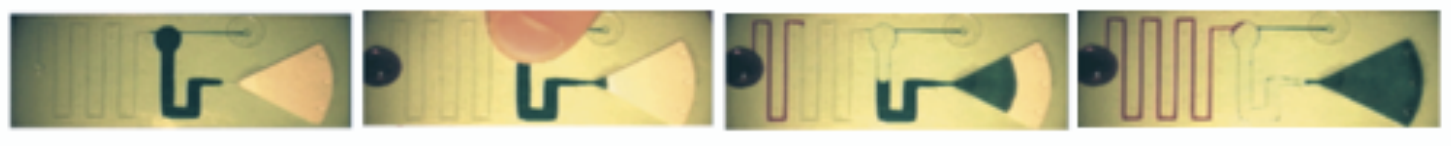

(c)
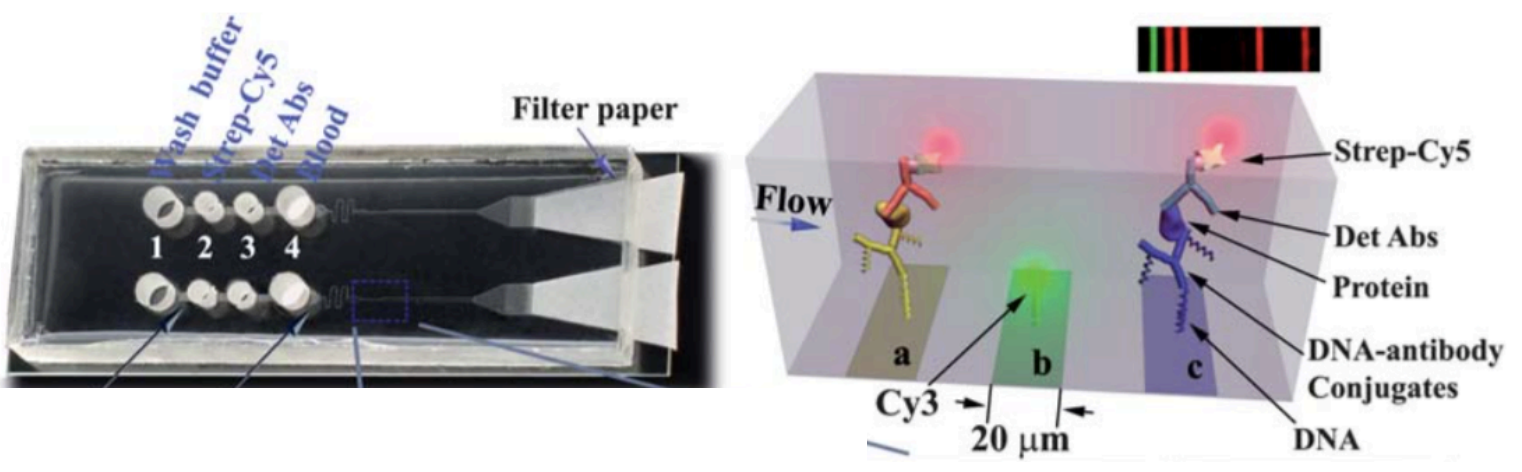

(d)
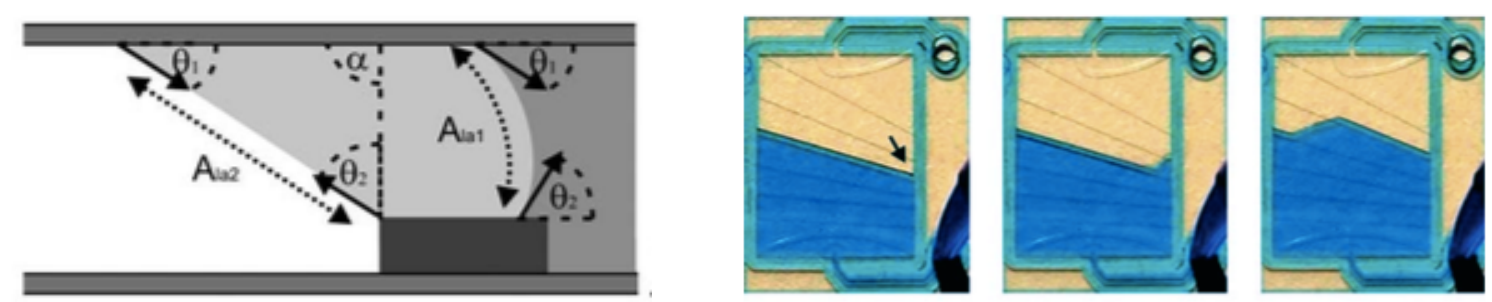

(e)

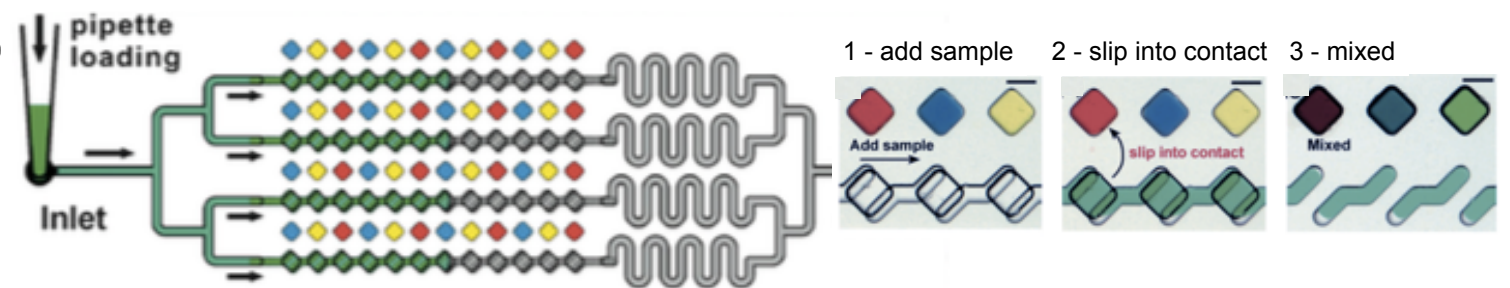

(f)

$$
\text { PUAg }
$$

$\mathrm{H}_{2} \mathrm{O}_{2} \rightarrow \mathrm{H}_{2} \mathrm{O}+1 / 2 \mathrm{O}_{2}$

chamber

chamber

(h) disposable ULOC

(g)
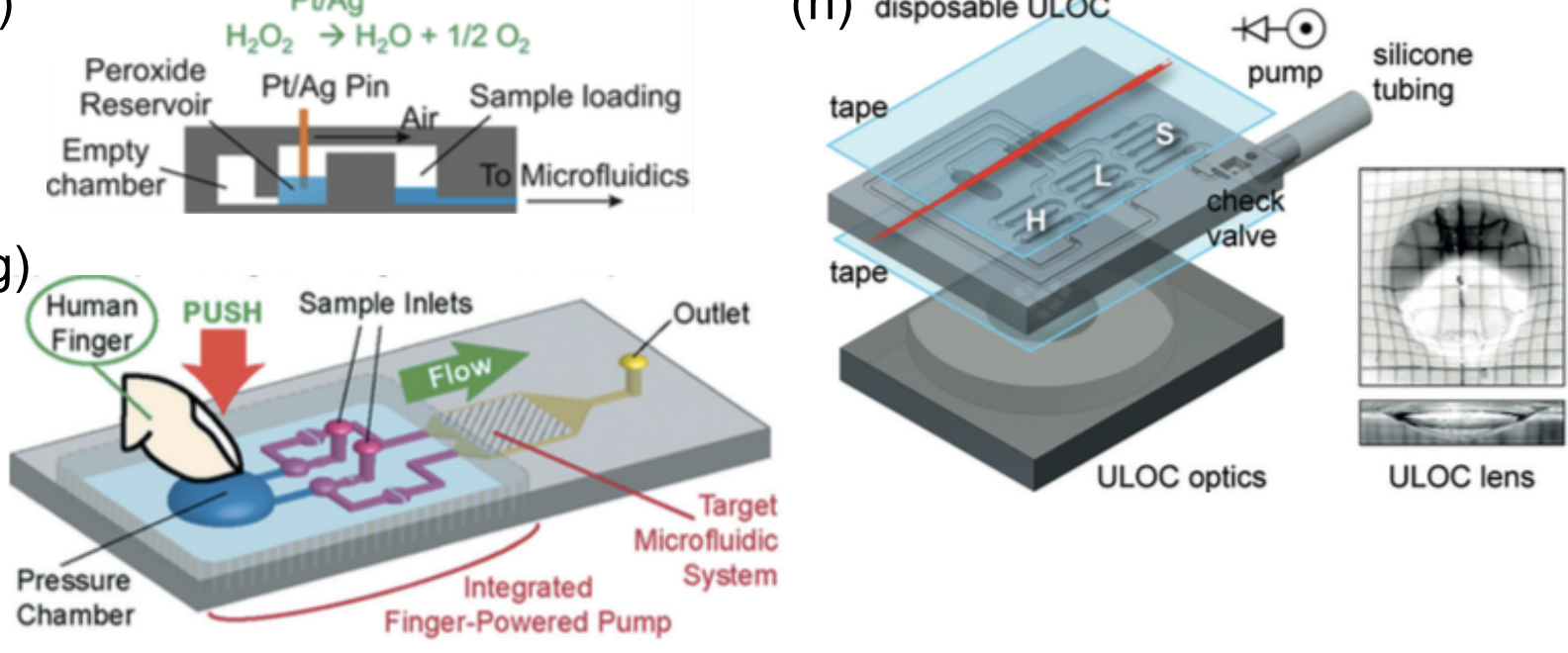
(a)

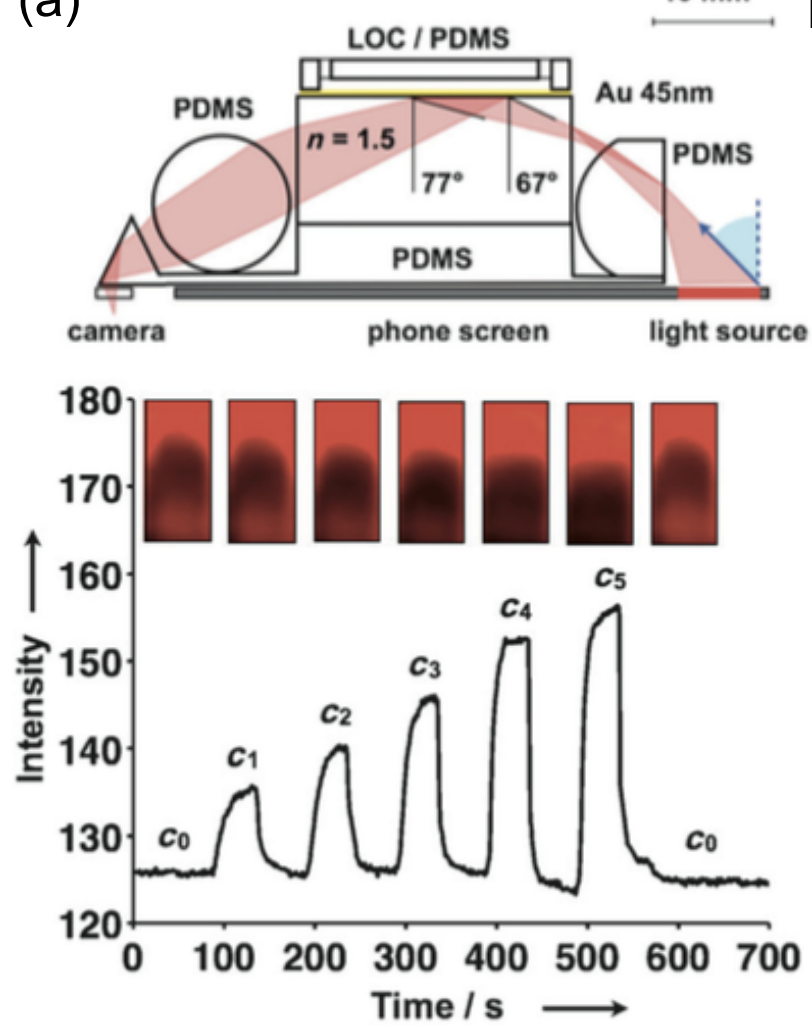

(b) Timer reactant (constant) Porous substrate

to

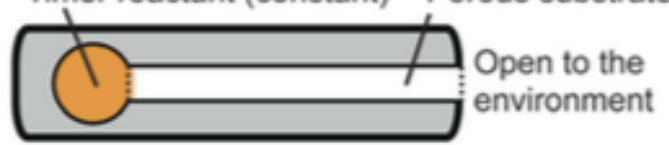

t1

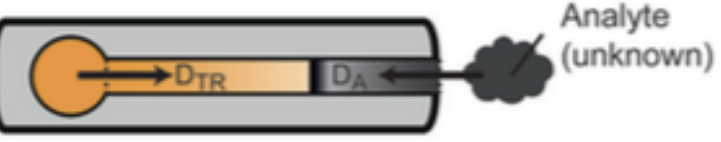

t2

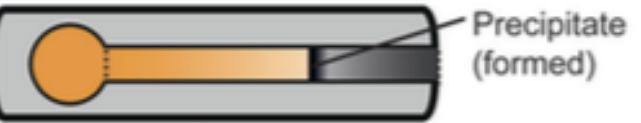

Position, $x$

Fig.5 (c)

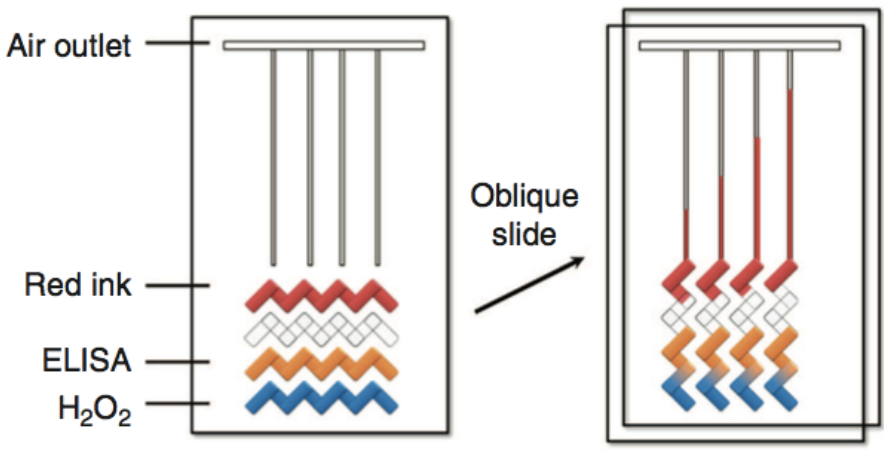

(d)

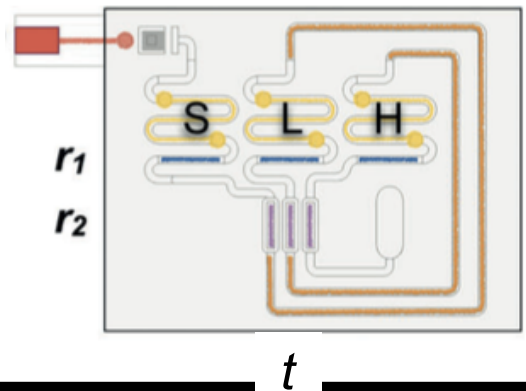

L

S

H

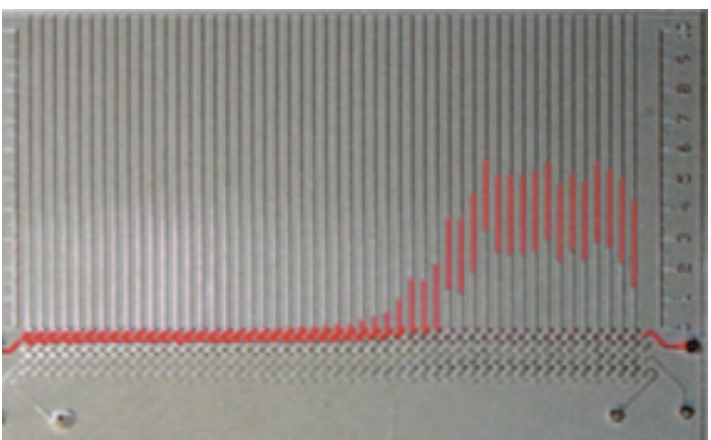

(e)

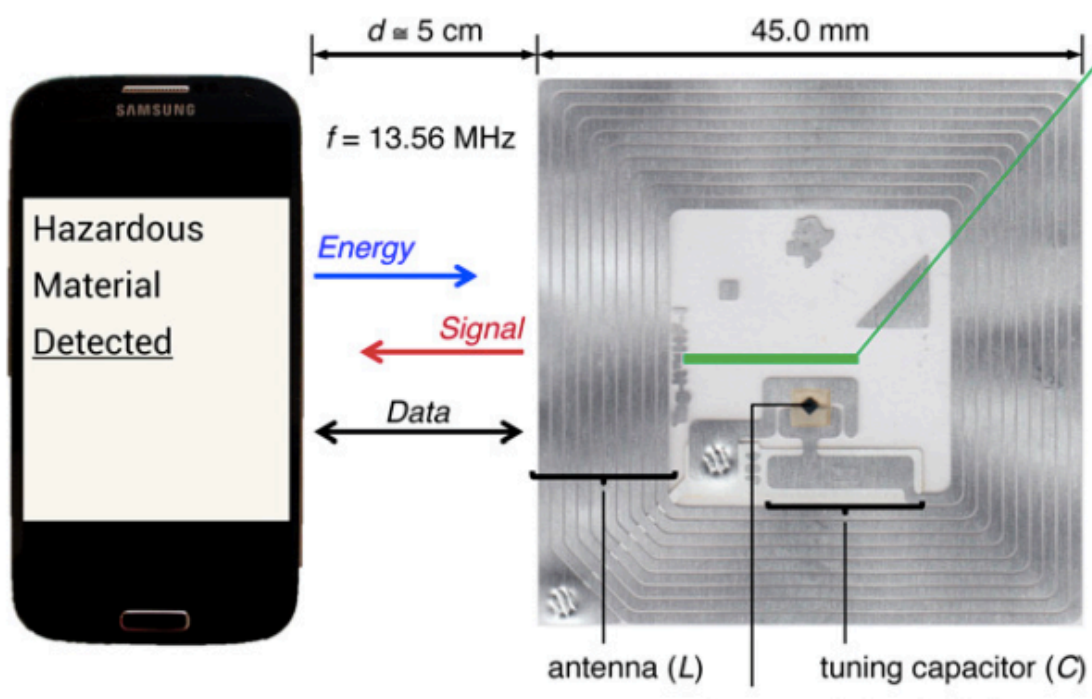

integrated circuit $\left(R_{I C}\right)$

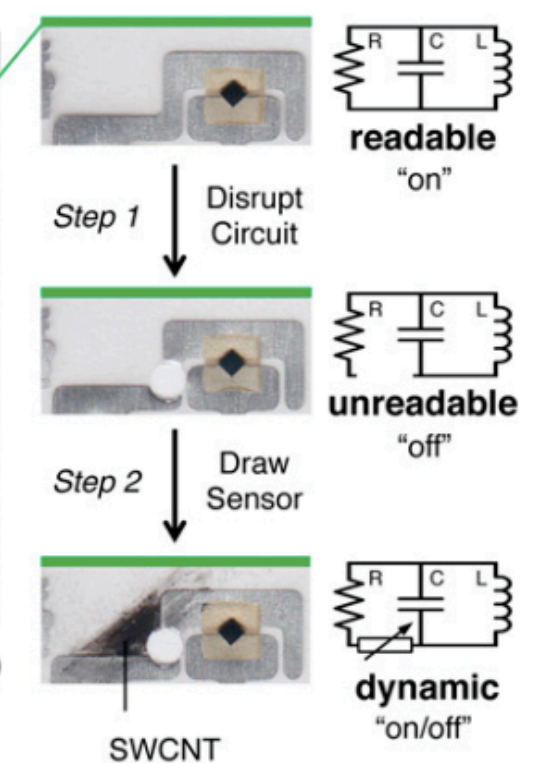

